\title{
Preservación del medio natural en los Reales Sitios del entorno de Madrid
}

\author{
Preservation of Natural Environment in the Royal Sites around Madrid
}

\author{
María del Pilar García Rodríguez ${ }^{1^{*}}$ (D) \\ Beatriz Álvarez García ${ }^{2}$
}

\section{Resumen}

El objetivo de este estudio es analizar la importancia que los Reales Sitios de la Comunidad de Madrid y de la provincia de Segovia tienen en la preservación de los territorios situados alrededor de sus palacios y que tienen un gran valor ecológico. El interés de los Reales Sitios como patrimonio histórico, artístico y turístico ha sido estudiado por numerosos investigadores; sin embargo, es menos conocida y estudiada su importancia en la conservación del patrimonio natural. Al tener un alto grado de protección ejercen de freno en la expansión urbanística, limitando el sellado del suelo y conservando el medio natural y la diversidad biológica. A pesar de la presión demográfica ejercida por Madrid, con un importante crecimiento de población en los últimos cincuenta años, que ha conducido a una expansión del suelo urbanizado, estos lugares siguen manteniendo gran parte de su espacio natural original. Aun así, el sellado ha fragmentado algunos territorios, por lo que se ha roto la conectividad entre estos Reales Sitios, lo que se observa claramente en las imágenes de satélite.

Palabras clave: Reales Sitios; sellado del suelo; espacios protegidos; conservación medio natural.

\begin{abstract}
The aim of this article is to analyse the relevance of the Royal Sites in Madrid and Segovia for the preservation of ecologically significant land around the palaces. The Royal Sites have been previously studied as part of the historical, artistic, and touristic heritage. However, their relevance in the preservation of natural heritage is less known. Given their high levels of protection, they act as a natural limit to urban spread, limiting soil sealing, and preserving the natural environment and biological diversity. Despite the demographic impact of Madrid, whose population has constantly grown over the last 50 years and produced an increasing sprawl of urban development, the Royal Sites have maintained their original landscape surfaces. Nevertheless, soil sealing has fragmented some of these territories and broken the connexion between them - as can be observed in satellite images.
\end{abstract}

Keywords: Royal Sites; soil sealing; protected landscapes; conservation.

1 Departamento de Geografía. Facultad de Geografía e Historia. Universidad Complutense de Madrid, España. mpgarcia@ucm.es. *Autora para correspondencia

2 Departamento de Historia Moderna y Contemporánea. Facultad de Geografía e Historia. Universidad Complutense de Madrid y Centro de Estudios de la fundación Carlos de Amberes, España. beatriz.alvarez@ucm.es 


\section{Introducción}

Uno de los problemas medioambientales más graves en Europa es el sellado de suelo debido a infraestructuras y urbanizaciones (Gardi et al., 2011; Agencia Europea de Medio Ambiente (AEMA) (2012); Munafo, Salvati y Zitti, 2012). Este sellado conduce a la desaparición de numerosos ecosistemas con graves consecuencias medioambientales (Añó, Pascual y Sánchez, 2005; Artmann, 2014; Romero, Belmonte, Docampo y Ruiz, 2011; Romero, Caballero y Pérez, 2017; Caballero, 2017; Shen, Abdoul, Zhu, Wang y Gong, 2017). La expansión de las áreas urbanas en las proximidades de las grandes ciudades (Scalenghe y Marsan, 2009; Munafo, Norero, Sabbi, y Salvati, 2010; Valera, Añó y Sánchez, 2011; Xiao et al., 2013) provoca la alteración de la dinámica natural del paisaje destruyendo grandes extensiones de vegetación natural e impidiendo la conexión entre los espacios naturales protegidos. Numerosos trabajos realizados en los últimos años sobre el sellado del suelo en la Comunidad de Madrid (García, Pérez y Guerra, 2014; García y Pérez, 2016; Pérez y García, 2016, 2017; Aréstegui y Pérez, 2017; García-Alvarado, García y Pérez, 2018a, 2018b; García Alvarado, Pérez y García, 2020; García y Álvarez, 2020) muestran cómo el crecimiento urbano supone un gran problema para el mantenimiento de los diversos ecosistemas y la conservación de los suelos (Comunidad Autónoma de Madrid (C.A.M.), 2007, 2010). Esta Comunidad y sus áreas aledañas han sufrido un importante proceso de urbanización y sellado del suelo debido al gran incremento de la población en los últimos cincuenta años. Así, según datos de la Comunidad Autónoma de Madrid (https://www.comunidad.madrid/) se ha pasado de 1.823 .410 habitantes en $1956 \mathrm{a}$ 6.662.000 en 2019. El incremento de la superficie urbanizada es, en proporción, muy superior, pasando de 11.850,39 hectáreas en 1956 a 81.183,30 en 2017. Sin embargo, este crecimiento no ha sido lineal, ya que el sellado se aceleró en la última década del siglo XX y primera del XXI. A partir de 2008, con la crisis económica se ralentizó el proceso de urbanización. Así, en 2005 el suelo urbanizado representaba el 9,74\% de la superficie de la C.A.M.; en 2008 el 9,86\% y en 2017 el 10,11\% por lo que el incremento en los últimos años ha sido menor. A pesar de ello, existen amplísimos espacios con vegetación natural en el Noroeste de la Comunidad, e incluso en el municipio de Madrid (36,25\% de suelo urbanizado en 2017) y en las áreas próximas a los cursos fluviales de toda la Comunidad. Un $48 \%$ del suelo de la Comunidad tiene un uso forestal. En la conservación de estos espacios juega un papel muy importante la existencia de los Reales Sitios que han preservado el patrimonio natural durante siglos.

Cinco Reales Sitios de la Comunidad de Madrid y la provincia de Segovia, además de palacios y edificios asociados, tienen una importante extensión de territorios naturales. Estos son gestionados por Patrimonio Nacional: jardines históricos, bosques y otros espacios naturales que, en conjunto, abarcan más de 22.000 hectáreas y albergan gran cantidad de fauna salvaje, con suelos frágiles y fácilmente erosionables y con formaciones vegetales representativas de distintos ámbitos: pinares, rebollares, bosque mediterráneo adehesado, sotos, bosques galería, etc. con gran valor medioambiental. Estos Reales Sitios se localizan en dos tipos diferenciados de paisajes:

- Paisajes forestales: superficies arboladas con distinto grado de cobertura y zonas de matorral. Dominan el pino silvestre (Pinus sylvestris) en las zonas más altas, el robledal de rebollo (Quercus pirenaica) en las intermedias y el bosque de encinas (Quercus ilex) en las más bajas. En estos paisajes se localizan los Reales Sitios de La Granja de San Ildefonso, Riofrío, El Escorial y El Pardo.

- Paisajes cerealistas y gipsófilos. En la cuenca sedimentaria del sur y sureste de la comunidad, sobre sedimentos calcáreos y yesos se desarrolla un paisaje dominado por con vegetación esteparia, plantas xerófitas y gipsícolas, con algunos enclaves de coscojares (Quercus coccifera), Gran parte del territorio está cultivado con cereales de trigo y cebada, olivos y vid. Destaca también el paisaje formado por sotos y riberas de los ríos con bosques galería y cultivos de regadío. Aquí se localiza en Real sitio de Aranjuez.

Un resumen de los principales paisajes e instrumentos de gestión y protección existentes en la actualidad en los Reales Sitios se recoge en la Tabla 1.

El objetivo de este estudio es analizar la importancia que la localización de los Reales Sitios de la Comunidad de Madrid y Segovia tienen en la preservación de territorios con amplio valor ecológico situados en las proximidades de una gran ciudad y, por tanto, sometidos a una gran presión urbanística. En este trabajo se analizan los paisajes representativos de estos lugares, la interconexión entre ellos y su evolución a través de la historia. Para ello se tienen en cuenta los datos que distintos autores han extraído al estudiar los planos históricos y se compara con la situación actual mediante el análisis de imágenes de satélite, que permiten tener una visión global de estos lugares. Por último, se comprueba si sigue existiendo 
interconexión entre ellos y si ha disminuido la extensión de sus áreas naturales. Los lugares seleccionados (Figura 1) son: El Escorial, La Granja de San Ildefonso y Riofrío, con amplias extensiones de bosques de pinos y robles; el Real Sitio de El Pardo caracterizado por un paisaje mediterráneo dominado por encinas; el Real Sitio de Aranjuez, con paisajes gipsíferos y formaciones de ribera con sotos que albergan numerosas especies endémicas. Aun cuando a lo largo de los siglos estos parajes naturales hayan perdido una extensión considerable, en la actualidad están muy protegidos, tanto por Patrimonio Nacional, como por las redes de espacios naturales, lo que asegura su conservación.

Tabla 1. Paisajes dominantes e instrumentos de planificación y gestión en los Reales Sitios

\begin{tabular}{|c|c|c|}
\hline SITIOS REALES & $\begin{array}{l}\text { PAISAJE DOMINANTE: } \\
\text { vegetación y suelos }\end{array}$ & $\begin{array}{c}\text { INSTRUMENTOS DE PLANIFICACIÓN } \\
\text { Y GESTIÓN }\end{array}$ \\
\hline El Pardo & $\begin{array}{l}\text { - Monte de encinas (Quercus ilex). } \\
\text { - Cambisoles, Arenosoles, Regosoles. }\end{array}$ & $\begin{array}{l}\text { - Patrimonio Nacional } \\
\text { - Reserva de la biosfera } \\
\text { - Parque Regional Cuenca Alta del Manzanares } \\
\text { - Red Natura } 2000 \\
\text { - ZEPA (Zona de Especial Protección para las aves), } \\
\text { ZEC (Zona Especial de Conservación), LIC (Lugar } \\
\text { de Importancia Comunitaria). }\end{array}$ \\
\hline San Lorenzo de El Escorial & $\begin{array}{l}\text { - Bosque de pinos y robles (Pinus } \\
\text { sylvestris y Pinus pinaster, Quercus } \\
\text { pyrenaica) y monte de encinas } \\
\text { (Quercus ilex). } \\
\text { - Leptosoles, Umbrisoles, } \\
\text { Cambisoles. }\end{array}$ & $\begin{array}{l}\text { - Patrimonio Nacional } \\
\text { - Monumento y Sitio de Patrimonio de la } \\
\text { Humanidad. UNESCO. Territorio histórico } \\
\text { - Red Natura } 2000 \\
\text { - LIC Cuenca del Guadarrama }\end{array}$ \\
\hline $\begin{array}{l}\text { La Granja de San Ildefonso } \\
\text { y Riofrío }\end{array}$ & $\begin{array}{l}\text { - Bosque de pinos y robles (Pinus } \\
\text { sylvestris, Quercus pyrenaica). } \\
\text { Vegetación higrófila. } \\
\text { - Umbrisoles, Leptosoles, } \\
\text { Cambisoles, Gleysoles. }\end{array}$ & $\begin{array}{l}\text { - Patrimonio Nacional } \\
\text { - Reserva de la biosfera } \\
\text { - Red Natura } 2000 \\
\text { - Parque Nacional del Guadarrama } \\
\text { - ZEPA, ZEC, LIC } \\
\text { - Plan de Ordenación cuenca del río Frío }\end{array}$ \\
\hline Aranjuez & $\begin{array}{l}\text { - Cultivos de regadío y vegetación } \\
\text { gipsícola e higrófila. } \\
\text { - Gipsisoles, Calcisoles, Regosoles y } \\
\text { Fluvisoles. }\end{array}$ & $\begin{array}{l}\text { - Patrimonio Nacional } \\
\text { - Paisaje cultural de la humanidad UNESCO } \\
\text { - ZEPA, ZEC, LIC }\end{array}$ \\
\hline
\end{tabular}

Elaboración propia

Figura 1. localización de los Reales Sitios
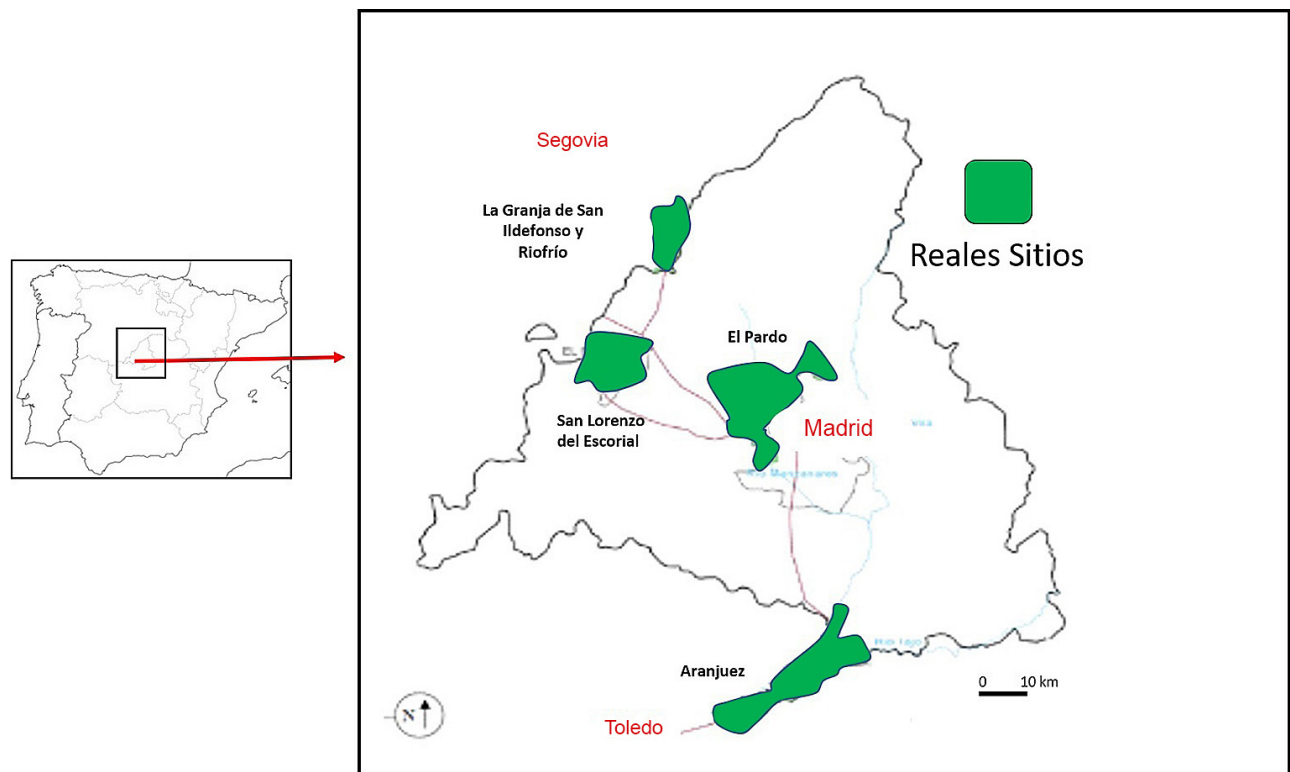

Fuente: Sancho (1995). Elaboración propia 


\section{Metodología}

En este estudio se ha utilizado una amplia bibliografía, en la que se incluyen planos históricos de los Reales Sitios, con el objetivo de analizar la composición de los paisajes naturales que rodean estos lugares y su evolución a través de los siglos. También se han analizado fotografías aéreas de vuelos desde los años cuarenta del pasado siglo, obtenidas en la página de la Comunidad de Madrid http:// www.madrid. org /cartografía/planeamiento e imágenes históricas del archivo del Plan Nacional de Ortofotografía Aérea (PNOA) histórico del Instituto Geográfico Nacional (http://www.ign.es). Para analizar la situación actual se han visualizado imágenes de los satélites Spot y Landsat (http://www.madrid.org/cartografia/planea/ planeamiento/) e imágenes actuales del PNOA (http://www.ign.es). Además, se ha seleccionado una imagen del satélite Landsat 8 obtenida en el servidor libre del United States Geological Survey.(USGS): http:// glovis.usgs.gov/ a la que se le han efectuado distintas mejoras espectrales (mezcla de bandas e índice de vegetación, NDVI) y se ha realizado una clasificación supervisada con el fin de comprobar si existe unión o no entre los Reales Sitios que permitan la conservación de sus suelos, vegetación natural y el movimiento de la fauna. En esta imagen se han realizado también correcciones geométricas y atmosféricas con el fin de obtener una mejor visualización. Se ha utilizado el software ERDAS Imagine 2019. La mezcla de bandas que mejor información visual ofrece es un falso color utilizando los canales 6,5 y 4 (IR próximos y rojo) del espectro electromagnético.

El Índice de vegetación de la Diferencia Normalizada se obtiene mediante la relación entre el canal Infrarrojo próximo menos el rojo partido por el cociente de la suma de ambos (IR-R/IR+R) que en el caso del satélite Landsat 8 corresponde a las bandas 5 y 4 respectivamente. El NDVI utiliza la alta respuesta espectral de la vegetación en el canal infrarrojo próximo frente a la baja en el canal rojo, por lo que las áreas con vegetación tienen valores positivos, mientras que los suelos sellados los tienen negativos.

La clasificación supervisada se ha realizado mediante el algoritmo paramétrico de la mínima distancia, ya que es el que ofrece más fiabilidad. A partir de la cartografía generada con esta clasificación, se ha calculado la superficie de suelos sellados y la superficie que aún mantiene vegetación natural.

Evidentemente, ha sido necesaria la comprobación directamente en el campo de las clases informacionales obtenidas, así como su comparación con imágenes de mayor resolución espacial como las que se obtienen con el PNOA.

Los datos de suelos se han adaptado a la Base Referencial Mundial del Recurso Suelo, 2015 (http:// www.fao.org/soils-portal/soil-survey/clasificacion-de-suelos/base-referencial-mundial/ es).

\section{Resultados}

En este apartado se analiza la importancia de estos lugares en la conservación de los ecosistemas y la evolución de los mismos.

\subsection{Importancia de los Reales Sitios en la preservación de los ecosistemas}

Con la denominación de Reales Sitios son conocidas las localizaciones donde se ubican las antiguas residencias de la familia real española, la mayor parte en las proximidades de Madrid, y que han sido utilizadas tradicionalmente como lugar de reposo, recreo, residencia de invierno o de verano y soto de caza, por los monarcas españoles. Estos Reales Sitios tienen su origen en la Baja Edad Media, momento en el que los reyes castellanos fueron cubriendo la geografía de sus territorios con residencias donde establecerse temporalmente, habida cuenta del carácter itinerante de la corte real. Aunque a lo largo de las décadas fueron aumentándose los territorios propiedad de la Corona, fue Felipe II quien llevó a cabo la primera sistematización y organización de dichos territorios. A través de la creación de la Junta de Obras y Bosques, la designación de un arquitecto mayor y el establecimiento de unas instrucciones para los oficiales de los Sitios Reales proporcionó a estos lugares su primera gestión y estructuración homogénea (Hortal, 2014), configurándolos como un todo que aún hoy permanece en su nomenclatura y gestión, puesto que pertenecen a Patrimonio Nacional. Los Sitios Reales estaban constituidos por bosques, jardines, espacios agrícolas, fábricas, núcleos urbanos, residencias palaciegas, iglesias y conventos y eran utilizados de forma estacional: los reyes residían habitualmente en El Pardo en invierno, Aranjuez en primavera, La Granja de San Ildefonso en verano y El Escorial desde mediados de octubre a diciembre. 
Como los Reales Sitios españoles, hay una gran cantidad de espacios naturales en Europa donde existen o existieron antiguos bosques y tierras adscritos a la realeza, lugares de reposo y esparcimiento que por ser propiedad de las Casas Reales se han preservado. La importancia del entorno paisajístico actuó como elemento de gran trascendencia en la elección de dichos enclaves para la ubicación en ellos de un Real Sitio, y sin el cual no se podrían comprender (Maroteaux, 2000).

Tales lugares han sido objeto de numerosos y excelentes estudios de investigación por parte de los historiadores (Tovar, 2001), de los historiadores de arte (Bonet, 2000; Checa y Morán, 1986), arquitectos y urbanistas (Chueca, 1989a,) entre otros. No obstante, Hortal (2017) señala que, hasta los últimos años, apenas si existen estudios en los que se haya abordado el sentido de tales palacios y jardines más allá de asignarles una función de descanso y divertimiento de los reyes y sus familias. Sin embargo, en los últimos tiempos, dichos lugares se están estudiando desde la metodología de los estudios de la Corte, a los que se suman las teorías del llamado giro espacial, con lo que cobran un significado mucho más relevante y se sitúan en el contexto de la formación y evolución de la organización política de la Monarquía Hispánica. De esta manera, se preservaron con mayor o menor fortuna. Estos Reales Sitios también tienen mucho interés como destino turístico (García y Mínguez, 2004) por lo que han sido analizados por numerosos investigadores señalando que los Reales Sitios adquieren mayor relevancia al tener un elevado valor paisajístico, no sólo vinculado al concepto tradicional de paisaje natural y al urbano, sino también al patrimonio cultural, que es el que refleja la importancia de determinadas figuras y episodios de la historia, acontecimientos, valores, gustos, aficiones y actuaciones (Mínguez, 2007).

Los Reales Sitios no solo comprendían espacios palatinos o funciones únicamente cortesanas. La explotación y aprovechamiento (leña, caza, pesca, cultivos, etc.) de los amplios espacios naturales que se desplegaron en torno a ellos los convirtieron en centros neurálgicos del poder político y económico y en espacios que transformaban y reestructuraban las zonas contiguas a ellos (Labrador y Rossi, 2014). Su localización geográfica no fue lo único que determinó su fundación, ya que también tuvo mucha importancia su entorno natural para ser utilizado como áreas de caza, hecho que ha permitido la gran diversidad biológica que se conserva en la actualidad. Ya en la Edad Moderna, la literatura cinegética de los siglos XVI, XVII y XVIII ofrece una geografía cinegética en la que se consignan sobre todo los cazaderos reales y algunos señoriales, principalmente castellanos y próximos a Madrid, de acuerdo con el centralismo de la época y con medios de desplazamiento poco eficaces. En la época de esplendor de este patrimonio y de los grandes reyes cazadores como Felipe IV, las fincas del Real Patrimonio o Reales Sitios eran las que siguen, según el duque de Almazán, 1934: la Casa de Campo, palacio y bosque de El Pardo, bosque de la Sagra, palacio y bosque de la Zarzuela, palacio Real de Valladolid y su ribera, palacio y bosque de Lomo de Grullo, Casa Real de la Fuenfría, palacio y bosque de Valsaín, casa y bosque de La Quemada, palacio y bosque del Albrojo, casa y bosque del Madrigal, palacio y bosque de Aranjuez, soto de Roma, palacio y bosque de El Escorial, palacio y bosque del Buen Retiro. (López Ontiveros, 1993). Los paisajes naturales fueron evolucionando al tiempo que lo hacía su uso. Así, durante el gobierno de la dinastía de los Austrias, estos terrenos eran dedicados fundamentalmente a caza, mientras que durante el reinado de los Borbones se dedicó más a uso recreativo y de paseo. Durante la Ilustración, algunos de estos terrenos se utilizaron como laboratorio para aplicar las nuevas prácticas agrícolas, lo que convirtió muchos de estos lugares en paisajes humanizados, el más notable de ellos en Aranjuez, con alto valor cultural e histórico, además de mantener su importancia ecológica. (Gómez y Atienza, 1998).

\subsection{Evolución del espacio natural}

Gracias a la presencia de los Reales Sitios existen amplísimas áreas verdes dentro del municipio de Madrid y su entorno. Algunos de estos lugares estaban unidos durante el siglo XVI, como El Escorial con el Real Sitio de El Pardo y este con el Soto de Viñuelas, si bien durante los siglos posteriores se fueron vendiendo propiedades de manera que quedaron aislados. Muchos de estos sitios han conseguido preservar la vegetación y suelos originales, aun estando muy próximos a un núcleo urbano en continua expansión como es la capital de España. Otros han desaparecido debido a la edificación, como el Real Sitio de la Florida (último en constituirse y primero en disgregarse), integrado en la ciudad de Madrid y situado en lo que hoy es Príncipe Pio, paseo de Rosales y Moncloa. De este antiguo Real Sitio queda ya solo el Parque del Oeste, los terrenos del Palacio de la Moncloa y la ermita de San Antonio de la Florida, este último integrado en la actualidad en el Patronato Real de Patrimonio Nacional. 
Pero no solo la extensión de la ciudad de Madrid afectó a estos lugares. La demanda de bienes suntuarios que protagonizaba la Corte atrajo hacia los Reales Sitios a algunas de las grandes manufacturas del siglo XVIII lo que afectó a los espacios naturales. Así, el establecimiento, en 1734, de la Real Fábrica de Vidrios y Espejos, impulsó el crecimiento urbano de San Ildefonso en detrimento de los bosques que los rodeaban, que fueron reduciéndose. Además de la caza estos espacios también se utilizaron para explotar recursos forestales y ganaderos y, en el caso de Aranjuez, sus recursos fluviales, con la utilización agrícola de la vega del río Tajo y la creación de áreas de recreo con amplios jardines. Por estas razones y otras de índole política, los Reales Sitios fueron disminuyendo su patrimonio natural a través de los siglos. En el siglo XIX hubo importantes cambios que afectaron a estos lugares. Urteaga y Camarero (2014a) señalan que en este siglo se enajenaron muchas de las propiedades. En total, se pusieron en almoneda dos terceras partes de la superficie de los antiguos Sitios Reales. En concreto, se declararon segregados y enajenables los siguientes bienes: algunas propiedades forestales correspondientes a los Reales Sitios de San Lorenzo de El Escorial y La Granja de San Ildefonso y parte de los de Aranjuez. En el Escorial se vendieron todos los montes, menos el de la Herrería. En San Ildefonso fueron enajenadas las Matas de Valsaín, pasando a dominio particular unas 3.000 hectáreas de monte. La enajenación más importante de El Pardo tuvo lugar a raíz de la revolución de 1869, cuando se vendieron en pública subasta como bienes nacionales las posesiones de la Moraleja y el Soto de Viñuelas (Sancho, 1995). En el caso de Aranjuez se segregó una gran parte de su territorio, aunque la enajenación no fue inmediata, ni completa; pero sí suficientemente desordenada y confusa como para dar lugar a una polémica política que se extendió hasta la Restauración. Las tierras regadas de la huerta de Aranjuez fueron vendidas casi de inmediato. Los nuevos propietarios adquirieron junto con la tierra el derecho al uso de las aguas para riego. El Estado retuvo tan sólo 913 hectáreas en la zona regada, incluyendo entre ellas 220 dedicadas a jardines. Asimismo, en 1931, la Casa de Campo, que había sido creada por Felipe II en la década de 1550 con el fin de dotar de una zona boscosa y de un soto de caza al alcázar, se convirtió en propiedad del ayuntamiento de Madrid (Sancho, 1995). Así, del antiguo conjunto de Reales Sitios tan sólo se dejó intacto el Real bosque de Riofrío.

Durante la década de 1860 la Junta General de Estadística desarrolló una amplia labor cartográfica para dar cumplimiento a la Ley de deslinde del Patrimonio de la Corona (1865), que ordenaba inventariar y cartografiar los Sitios Reales. En sucesivas campañas topográficas, en las que tomaron parte más de un centenar de geómetras y parceladores, llegaron a levantarse más de 60.000 hectáreas de las posesiones reales en las provincias de Madrid y Segovia. En total, se dibujaron alrededor de 2.750 hojas de mapas a distintas escalas. La evolución de estos lugares se puede ver en los mapas que posee el Instituto Geográfico Nacional y que Urteaga y Camarero (2014a y 2014b) han recogido y analizado en sus estudios.

En la actualidad, como se puede observar en la imagen del satélite Landast 8 de octubre de 2018 (Figura 2), los espacios naturales de San Ildefonso-La Granja y Riofrío están prácticamente unidos con una amplia vegetación forestal. Asimismo, a través de las cimas del Sistema Central enlazan con los parajes de Cuelgamuros y El Escorial. Por el contrario, la unión que existía en siglos pasados entre estos Reales Sitios y el Real Sitio de El Pardo ha quedado rota con una importante fragmentación de los paisajes naturales debido a la presencia de infraestructuras viarias y urbanizaciones (en tono azul oscuro) que separan ambos parajes, si bien puede haber algunos pasos entre El Pardo y El Escorial a través de los montes de encinas y dehesas. Alejado de ellos se localiza el Real Sitio de Aranjuez separado por la ciudad de Madrid y municipios del área metropolitana, así como por las importantes infraestructuras viarias asociadas a ella.

En la imagen se observa en verde los bosques de robles y coníferas en el Sistema Central (La Granja, Riofrío y El Escorial) y las parcelas de cultivos de regadío y vegetación higrófila en las proximidades de Aranjuez. En violeta oscuro, bosques de formaciones mediterráneas (encinar) en El Pardo. En azul oscuro áreas urbanizadas e infraestructuras viarias. En el sureste de la imagen se observa en tonos muy claros el paisaje estepario y las parcelas de secano que están en barbecho o en las que aún no han crecido los cultivos. Los afloramientos de yeso aparecen en tonos blanquecinos en las proximidades del Real Sitio de Aranjuez.

La cartografía de estos parajes naturales se puede realizar mejor obteniendo el Índice de vegetación de la Diferencia Normalizada (Figura 3) en la que destaca en color blanco la presencia de las masas forestales que unen los Reales Sitios en el noroeste de la imagen. También se ve, en tonos claros, la vegetación de ribera de los ríos Tajo y sus afluentes, que sirven además de corredores ecológicos para la fauna. 
Figura 2. Imagen en falso color del satélite Landsat 8, 3-10-2018. Bandas 6-5-4 (R-V-A)

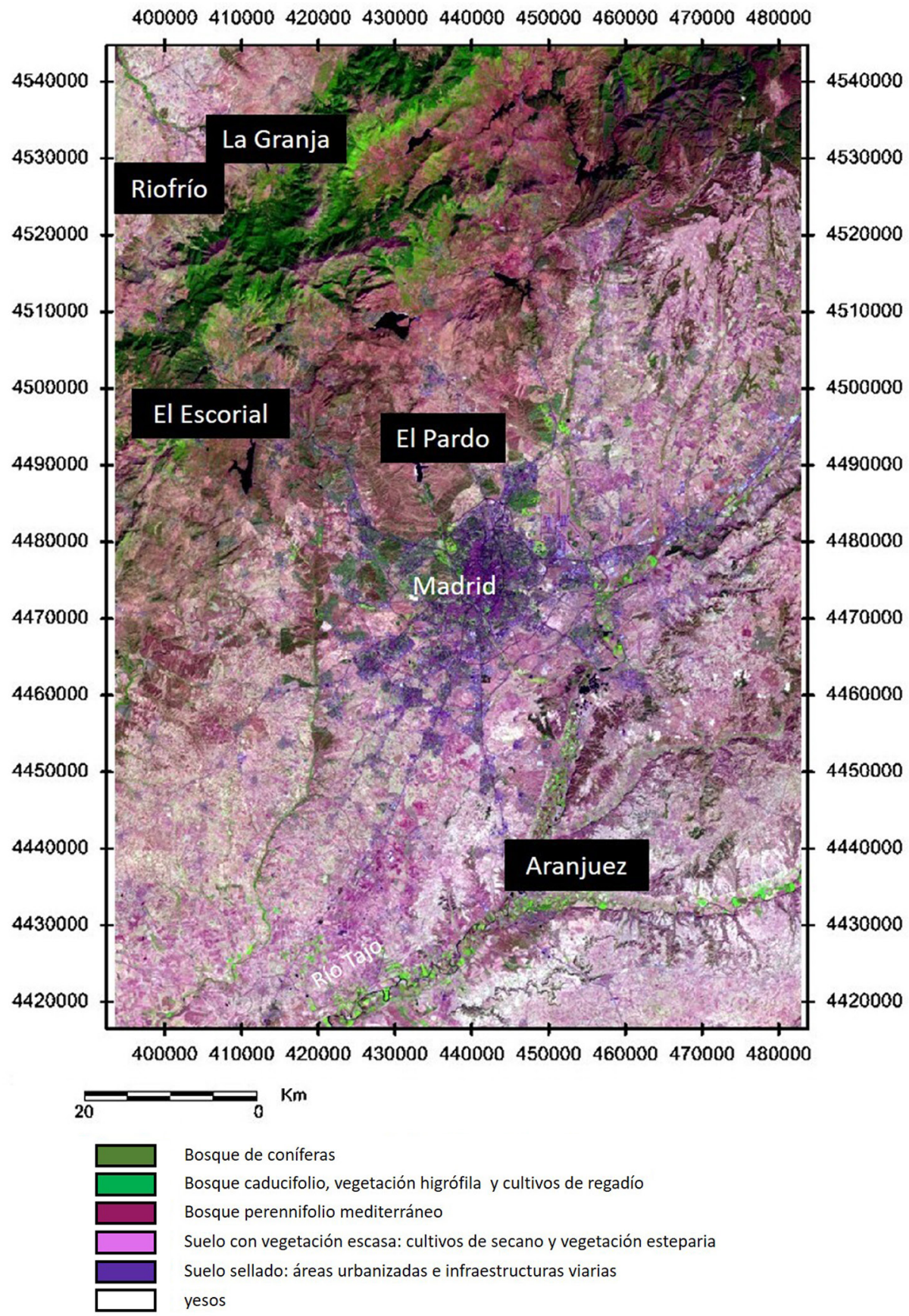

Fuente: http://glovis.usgs.gov/. Elaboración propia

En la imagen se observa en tonos blancos la vegetación que tiene más actividad clorofílica correspondiente a bosques caducifolios y parcelas de cultivos en regadío. En gris claro la vegetación perennifolia, tanto los bosques de coníferas como las formaciones de encinares y coscojares. En negro, suelos desnudos o sellados y las masas de agua.

Con la imagen de satélite se ha realizado una clasificación supervisada para tratar de cartografiar con más precisión los paisajes naturales asociados a los Reales Sitios (Figura 4). Se han establecido siete clases: vegetación de frondosas y regadíos, bosques de coníferas, vegetación mediterránea, suelos desnudos (bien por estar en barbecho o por no tener apenas vegetación), suelos sellados por viviendas e infraestructuras y agua. 
En esta clasificación se puede observar cómo existe una unión en los bosques de Riofrío, La Granja de San Ildefonso y El Escorial, por lo que ambas áreas con vegetación de coníferas y/o frondosas permanecen unidas a los dos lados del Sistema Central. Por el contrario, en las proximidades de El Monte de El Pardo se puede observar que el sellado de suelo ha fragmentado su unión con los Reales Sitios situados en el Sistema Central. Esta fragmentación constituye un importante deterioro de los ecosistemas, ya que, según Rodríguez y Martínez (2019), los cambios en los usos del suelo tienen como consecuencia inevitable la parcelación y erradicación progresiva de los hábitats originales, que van reduciendo su tamaño y quedando aislados, separados entre sí por una matriz de hábitats de nueva creación. Los principales resultados de esta fragmentación son la pérdida y degradación del hábitat y la pérdida de conectividad (Herrera y Díaz, 2013), lo que reduce de forma significativa la viabilidad futura de los ecosistemas y, por ende, de la biodiversidad (C.A.M., 2010).

Figura 3. NDVI (B5-B4/B5+B4) de la imagen Landsat 8 del 3-10-2018
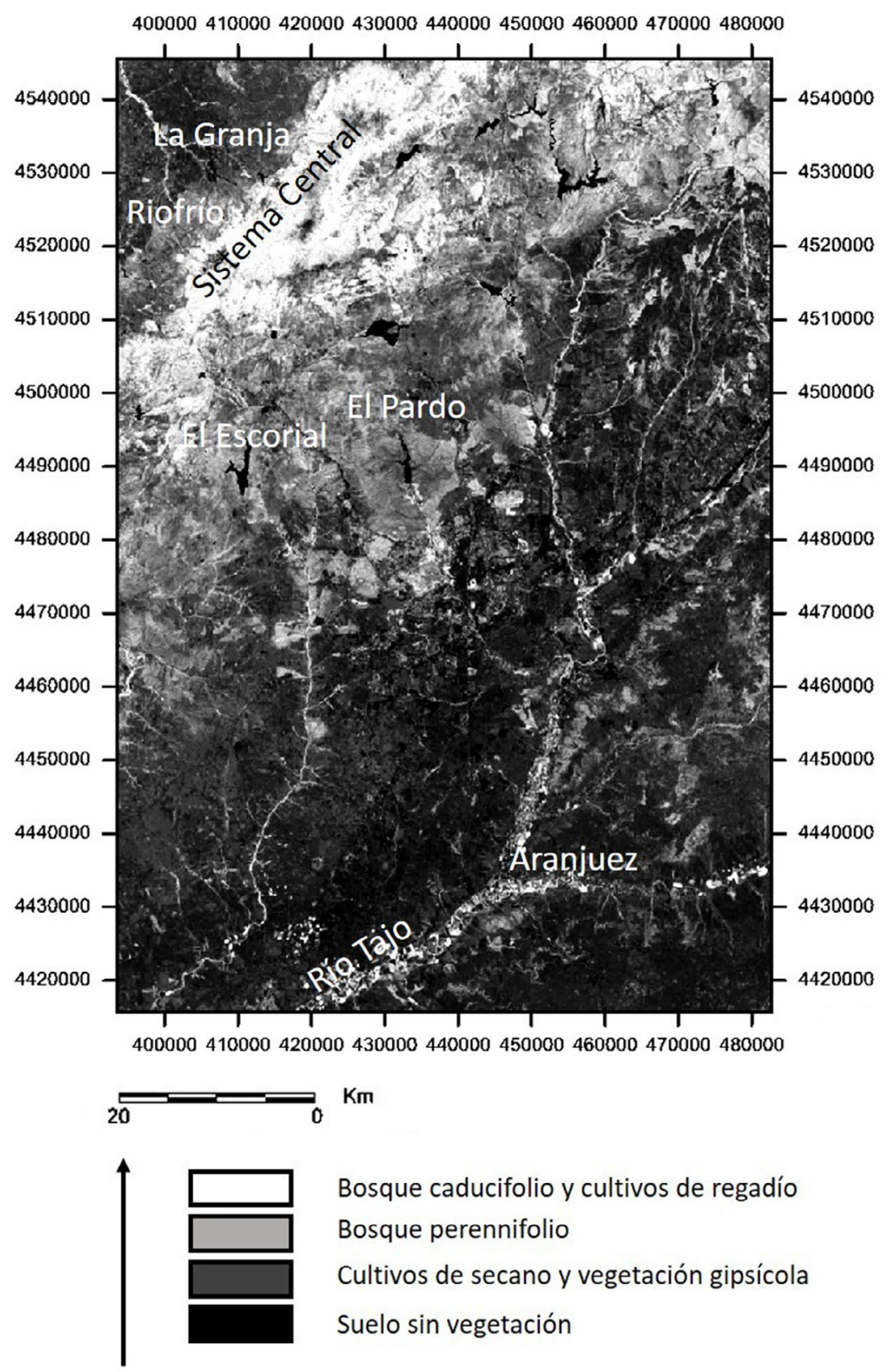

Incremento actividad clorofílica

Fuente: http://glovis.usgs.gov/. Elaboración propia 
Figura 4. Clasificación supervisada de la imagen Landsat 8

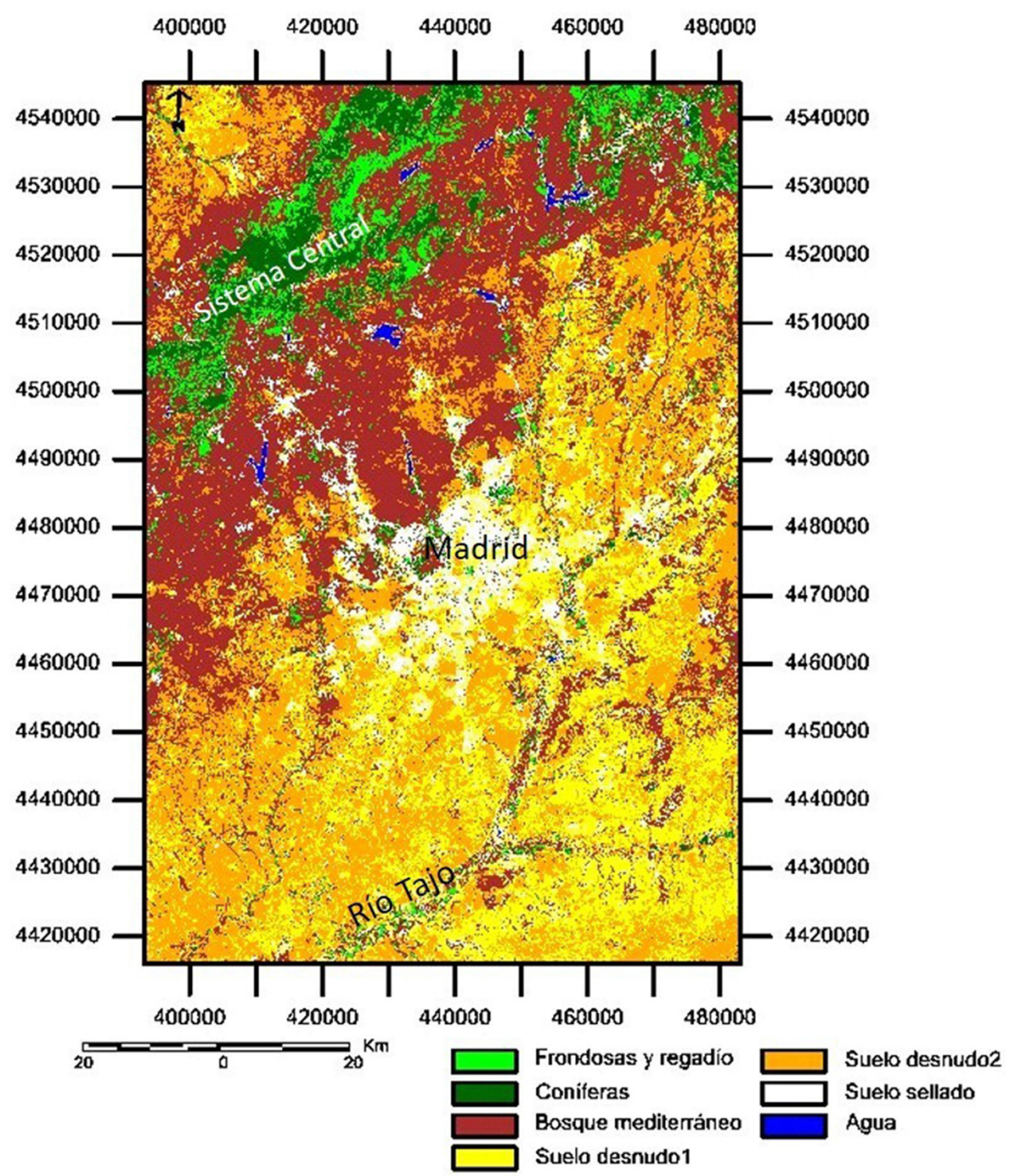

Fuente: http://glovis.usgs.gov/. Elaboración propia

También se puede observar en este mapa cómo en Aranjuez se mantiene un importante corredor fluvial formado por vegetación higrófila y parcelas de regadío.

Aproximadamente el suelo sellado en la escena analizada ocupa unas 86.000 hectáreas, frente a unas 512.000 hectáreas de vegetación natural.

\subsubsection{Real Sitio de el Monte de El Pardo}

En 1405 el rey Enrique III de Castilla mandó construir una quinta de caza en medio del Monte de El Pardo. Ampliada en tiempos de Enrique IV, la quinta fue demolida durante el reinado de Carlos I, y sustituida por un palacio de jornada, proyectado por el arquitecto Luis de Vega. Durante el reinado de Fernando VI los dominios del Real Sitio se ampliaron mediante la adquisición del Monte de Viñuelas, que fue incorporado en 1751. El rey Carlos III le dio el impulso definitivo. Durante su reinado, el arquitecto Francisco Sabatini reordenó por completo las fachadas del Palacio Real, y se reformaron los jardines anexos. Muy cerca del Palacio Real se construyó un pequeño palacete, denominado la Casita del Príncipe, utilizado como lugar de descanso por los príncipes de Asturias, Carlos y María Luisa. También se procedió 
a la ampliación y renovación de la pequeña población de El Pardo, que había crecido en las proximidades del Palacio (Urteaga y Camarero, 2014a). En 1762, El Pardo, ya como propiedad real, se extendía desde Alcobendas a Torrelodones de este a oeste, y desde Colmenar a Madrid por la línea norte sur. Sin embargo, su extensión se fue reduciendo a lo largo de los años. En el levantamiento del plano realizado entre 1861 y 1866 tenía, junto al Soto de Viñuelas, 19.807 Ha, (Urteaga y Camarero, 2014a).

En la actualidad tiene una superficie de 15.821 hectáreas, cerrado por una cerca de casi $100 \mathrm{~km}$ de longitud que mandó construir Fernando VI y El Soto, aislada de él, unas 2.900 Ha y como se observa en las imágenes de satélite estas áreas apenas están unidas por una pequeña franja de bosque mediterráneo. Existe una amplia zona donde se ha sellado el suelo por infraestructuras y urbanizaciones, especialmente, hacia el noroeste (Figuras 2 y 3 ).

Por esta razón el espacio natural que unía los diferentes Sitios Reales del noroeste de Madrid se fragmentó. Aun así, el Monte de El Pardo se preservó casi en su totalidad, como se puede observar en la imagen de satélite y en la clasificación de ocupación del suelo realizada a partir de ella (Figura 4) Al ser un coto de caza durante siglos, ha escapado a la destrucción del entorno natural que sí se ha producido en áreas próximas, debido al sellado de suelo como consecuencia del crecimiento de la capital. Aun así, a lo largo del siglo XX se segregaron numerosos terrenos para edificación e infraestructuras como la Nacional VI. A pesar de ello se preserva la mayor parte del territorio, ya que el área protegida supera las 14.750 . Ha. Es un testimonio del paisaje de antaño, un lugar en el que se mantiene la fauna y la flora originales, donde existe además un centro urbano, El Pardo, integrado a dicho espacio natural y una residencia real, el Palacio de El Pardo, donde se conserva un importante conjunto arquitectónico y artístico.

Actualmente, se encuentra dentro del Parque Regional de la Cuenca Alta del Manzanares, constituido en 1985 mediante la Ley 1/1985 de 23 de enero y que ha sido objeto de sucesivas modificaciones posteriores, de las cuales las más destacadas corresponden a las ampliaciones de los años 1987 y 1991 . Aunque el Parque cuenta con un Plan Rector de Uso y Gestión (PRUG), aprobado en 1987 y revisado en 1995, que regula los distintos parajes incluidos, el Monte de El Pardo depende de Patrimonio Nacional por lo que su protección es aún mayor, ya que este Organismo impide las visitas públicas en gran parte de su extensión. El 15 de febrero de 1993, el parque regional de la Cuenca Alta del Manzanares recibió la declaración de Reserva de la biosfera por parte de la Unesco y, más tarde, el Monte de Viñuelas fue reconocido como Zona Especial de Protección para Aves (ZEPA). Este monte está incluido en la Red Natura 2000, en el LIC de Guadarrama y en la ZEPA, por lo que, a pesar de su fragilidad, queda protegido. Además 15.289 Ha del monte han sido declaradas Zona de Especial Protección para las Aves (ZEPA), con el objeto de conservar y proteger el águila imperial ibérica.

El Monte de El Pardo, caracterizado por dos paisajes representativos, la dehesa y la vegetación de ribera, está formado por sedimentos miocenos de arenas y arcosas, con materiales cuaternarios en las vegas de los ríos (Instituto Geológico y Minero de España [IGME], 1989, 2000), sobre los que se desarrollan Cambisoles eútricos, Regosoles dístricos y Arenosoles (Monturiol y Alcalá, 1990a), que sustentan un paisaje adehesado de monte arbolado, constituyendo uno de los bosques mediterráneos mejor conservados de la península ibérica. Comprende la vega del Manzanares, incluido el embalse de El Pardo y los depósitos terciarios de arcosas sobre los que se desarrollan encinas y coscojas, con presencia de alcornoques, quejigos, enebros y vegetación higrófila de ribera (sauces, olmos, fresnos, chopos, etc.). La vegetación arbustiva es la característica de las formaciones de durifruticeta con presencia de retamas, jarales y plantas aromáticas. La fauna tiene mucha importancia puesto que en este monte habitan jabalíes, ciervos, gamos, zorros y numerosas especies de aves entre ellas el águila imperial, el buitre negro y el búho real. La poca consistencia de sus materiales y la fragilidad de sus suelos es responsable de que tenga una baja capacidad agrológica (clases C y D, Monturiol y Alcalá, 1990b) con alto riesgo de erosión, por lo que su protección es imprescindible.

El mismo tipo de materiales, suelos y vegetación se localiza en el Soto de Viñuelas. Ambos parajes, unidos en el pasado, se encuentran ahora separados al norte por el municipio de Tres Cantos y sus infraestructuras viarias asociadas y, al sur, por Alcobendas y San Sebastián de los Reyes, aunque, como se observa en las imágenes de satélite (Figuras 1 y 2), hay una estrecha franja de monte que permite el intercambio de fauna terrestre.

\subsubsection{Real Sitio de San Lorenzo de El Escorial}

En 1561 Felipe II decidió la actual ubicación del Monasterio y adquirió los terrenos donde habría de construirlo, así como los colindantes necesarios para crear un coto real de caza y disponer de pastos para 
el ganado y huertas de abastecimiento de los monjes. Todo ello lo cercó con un muro de piedra de $2 \mathrm{~m}$ de altura y $50 \mathrm{Km}$ de perímetro (Cerca Histórica de Felipe II). Hacia finales del siglo XVI, los límites del Real Sitio de El Escorial eran extraordinariamente vastos, teniendo una continuidad física con los lindes del Monte de El Pardo. La inmensa mayoría de estas propiedades fueron vendidas en 1870 por el Estado a particulares, como consecuencia de las leyes desamortizadoras del Sexenio Revolucionario, y sólo se conservan adscritas al Patrimonio Nacional las fincas de La Herrería, El Cerrado, El Romeral y El Navazo de la Pulga. En el siglo XVIII se construyeron dentro de la Herrería las Casitas del Príncipe y del Infante con sus respectivos parques y jardines (Patrimonio Nacional, 1997).

El Monasterio de El Escorial, situado en la vertiente meridional de la Sierra de Guadarrama, fue el verdadero centro político de la Monarquía Hispánica durante el último tercio del siglo XVI. Alrededor del monasterio se constituyó un extenso señorío, con una superficie superior a las 10.000 ha. La construcción del gigantesco monasterio, iniciada en 1563, transformó por entero el sistema de asentamientos preexistente, comenzando por la pequeña aldea de El Escorial convertida en una villa de realengo (Urteaga y Camarero, 2014b).

El entorno natural de la Herrería y del monte de Abantos en San Lorenzo de El Escorial recibieron en el año 1961 un distintivo nacional al ser considerados legalmente cada uno de ellos como Paraje Pintoresco, y en ese mismo año se les concedió la protección de Bienes de Interés Cultural, bajo la categoría de Sitio Histórico, calificaciones jurídicas que condicionan la conservación y las actuaciones que pueden ser llevadas a cabo en este lugar, controlándose mucho más, desde el punto de vista urbanístico y edificatorio, que otros espacios. Este hecho se ve reforzado por la declaración de Monumento y Sitio del Patrimonio de la Humanidad, que fue concedida en el año 1982 (Mínguez, 2007).

Los terrenos sobre los que se asienta el Real Sitio están formados por materiales sedimentarios de bloques y cantos de granito en San Lorenzo de El Escorial, adamellitas biotíticas en El Escorial y ortoneis glandulares y leuconeis al norte del mismo, con glacis cuaternario en La Herrería (IGME, 1990). Los suelos corresponden a Cambisoles dístricos y Umbrisoles y, en las áreas con más pendiente, a Leptosoles líticos. Su uso está condicionado por la pendiente, perteneciendo a la clase agrológica D con riesgo de erosión y poco espesor del suelo (Monturiol y Alcalá, 1990b). Desde su construcción tuvo mucha importancia su uso agroforestal y ganadero, con pastos y bosques en las zonas altas y un paisaje de dehesas en las zonas más bajas. Sobre los Cambisoles y Umbrisoles, se desarrolla un bosque formado, en su mayor parte, por robles. En menor medida aparecen castaños, arces, enebros, sauces, y, en las zonas más húmedas, fresnos. El estrato arbustivo está dominado por las retamas y genistas. Gran parte de su superficie constituye una dehesa con presencia de pastos. Los mamíferos más emblemáticos que habitan el bosque son los corzos, los jabalíes, los zorros y las garduñas, con presencia del gato montés y la nutria. Hay multitud de pequeñas aves insectívoras como herrerillos, carboneros, papamoscas; y otras como mochuelos, arrendajos, y pájaros carpinteros. Destacan la presencia de cormoranes, abejero europeo, pico menor y la chova piquirroja (https://www.patrimonionacional.es). Mediante el decreto 2418/1961, de 16 de noviembre (B.O.E. $\mathrm{n}^{\circ} 292$ de 07/12/1961) se protege una superficie de aproximadamente 1.171 ha situadas mayoritariamente en San Lorenzo de El Escorial y, en menor medida, en Santa María de la Alameda denominado Paraje Pintoresco de El Pinar de Abantos y zona de la Herrería. Combina extensiones de un espeso pinar (Monte Abantos) y de una amplia zona en la que predominan los quejigos y los fresnos (La Herrería).

Al municipio de San Lorenzo de El Escorial corresponde también el valle de Cuelgamuros, formado por materiales graníticos con desarrollo de Cambisoles y, en las zonas con más pendiente, Umbrisoles y Leptosoles. El bosque es de repoblación con presencia de pinares de Pinus sylvestris y Pinus pinaster. Según Patrimonio Nacional (https://www.patrimonionacional.es/), "Cuelgamuros presenta una gran diversidad de comunidades vegetales: pinares de pino resinero y pino silvestre, rebollares mixtos, fresnedas, cipreses y arizónicas, praderas, choperas, abedulares, alisedas y saucedas, destacando la existencia de un hayedo naturalizado, enebros, tejos centenarios o singulares alcornoques, y de paisajes: roquedos, canchales, barrancos, praderas o bosques en galería".

Tanto los paisajes pertenecientes al Real Sitio de El Escorial como el valle de Cuelgamuros están incluidos en la Red Natura 2000, pertenecientes al LIC de la Cuenca del Guadarrama Con 34.109 hectáreas de superficie conforma un espacio que queda determinado por el eje del río Guadarrama y por los relieves serranos de la zona de Abantos y La Herrería en San Lorenzo de El Escorial, y la zona del Embalse de la Jarosa en el municipio de Guadarrama. Este LIC queda conectado con el de la Cuenca del río Manzanares y con el Parque Regional de la Cuenca Alta del Manzanares. Los ríos Guadarrama y Manzanares ejercen 
de corredores verdes manteniendo todas las relaciones ecológicas, la vegetación higrófila de ribera y su fauna asociada y la unión de los bosques caducifolios y perennifolios de la ladera sur de la Sierra.

El 15 de junio de 2006, se realizó la última de las Declaraciones de Bien de Interés Cultural en uno de los Reales Sitios y ha servido para declarar íntegramente al Real Sitio de San Lorenzo de El Escorial como Territorio Histórico. Este espacio queda constituido por el ámbito delimitado por la Cerca Histórica de Felipe II, lo que supone una superficie de 99 millones de metros cuadrados que, con su entorno de protección, alcanza 120 millones de metros cuadrados, limitados por un territorio que se extiende por los municipios de San Lorenzo de El Escorial y El Escorial y una pequeña parte de Zarzalejo y Santa María de la Alameda.

\subsubsection{Real Sitio de La Granja de San Ildefonso y Riofrío}

Dentro de la red de Reales Sitios que rodean la ciudad de Madrid, el de San Ildefonso ocupa un lugar especial. Es el más alejado de la capital, el único situado fuera de la provincia de Madrid, el más boscoso y el de relieve más accidentado. La posesión real de San Ildefonso tiene su límite oriental y meridional en la línea de cumbres de la Sierra de Guadarrama, que separa las provincias de Segovia y Madrid, y que alcanza su máxima altura en Peñalara $(2.428 \mathrm{~m})$. Desde las cimas de la Sierra el terreno desciende abruptamente hasta alcanzar la planicie segoviana, sobre los $1.200 \mathrm{~m}$ de altitud. La vertiente septentrional de la Sierra está poblada por densos bosques de roble y pino silvestre, conocidos como los Pinares de Valsaín. La superficie del Real Sitio supera las 14.000 hectáreas, de las cuales casi un $80 \%$ son bosques (Urteaga y Camarero, 2014b).

Los bosques de Valsaín ya eran coto de caza de los reyes castellanos en la Edad Media. En 1720, tras el incendio del palacete de Valsaín, Felipe $V$ decidió comprar a la comunidad de frailes jerónimos la granja y los edificios y terrenos anejos que tenían en San Ildefonso, para construir en aquel lugar un palacio y sus correspondientes jardines. En 1723 y 1735 se adquirieron terrenos colindantes que pertenecían a la ciudad de Segovia y a la Noble Junta de Linajes, para ensanchar el parque y regularizar su perímetro (Sancho, 1995). Durante el reinado de Felipe V, San Ildefonso ingresó en el sistema de Sitios Reales que la Corte utilizaba de modo itinerante (Bonet, 2000).

Los terrenos de Riofrío fueron arrendados a principios del siglo XVIII, por Felipe V como coto de caza. En 1751 Isabel de Farnesio los adquirió con el objetivo de levantar el actual Palacio. Posteriormente, la Reina incrementó la extensión de la finca mediante la adquisición de terrenos colindantes a base de compras y permutas. Otras incorporaciones se llevaron a cabo durante los reinados de Carlos IV e Isabel II, resultando un bosque que no fue afectado por las ventas de propiedades del Real Patrimonio en el siglo XIX. Se encuentra rodeado en todo su perímetro por una tapia de mampostería. Situado a $15 \mathrm{~km}$ del núcleo municipal, San Ildefonso, tiene una extensión de 640 Ha y constituye una importante reserva ecológica y biológica en los cuatro ecosistemas que lo representan: encinar, sabinar, rebollar y fresneda, (Sancho y Aparicio (2012).

Los Reales Sitios de la Granja y Riofrío localizados en las estribaciones del Sistema Central en la provincia de Segovia con una altitud entre los $1.086 \mathrm{~m}$. y $950 \mathrm{~m}$ se asientan sobre materiales ígneos del Paleozoico, adamellitas porfídicas en La Granja y ortoneis glandulares en Riofrío (IGME, 1991). Los suelos corresponden a Ranker, Cambisol húmico y dístrico, Litosuelos y Gleysol húmico (Forteza et al. 1987; Gallardo, Álvarez y Cala, 1988), Cambisoles húmicos en Valsaín (Jiménez, García, Polo y Almendros, 1981) y en San Ildefonso (Nicolás y Gandullo, 1969). La vegetación dominante está constituida por robles (Quercus pirenaica) y pinos (Pinus sylvestris), explotados desde la Edad Media para madera, con enclaves de quejigos (Quercus faginea) y arces de Montpellier, con sotobosque de retamas y plantas aromáticas y, en las riberas del río Riofrío, vegetación higrófila de chopos y álamos. La diversidad faunística del bosque de Riofrío es considerable con más de 50 especies de aves, entre ellas el buitre leonado y el buitre negro. También lo habitan numerosas especies de mamíferos (ciervo, gamo, conejo, tejón, zorro, gineta y comadreja) y reptiles. En total hay 102 especies catalogadas, de las que 42 están protegidas y 8 en peligro de extinción. El bosque de Riofrío está dentro del Plan de Ordenación de los Recursos Naturales de la cuenca del río Riofrío y está incluido en la Red Natura 2000 con el título de "lugar de interés comunitario" (LIC). Está situado dentro de la zona de especial protección de aves (ZEPA) "Valles del Voltoya y el Zorita" y zona de especial conservación (ZEC). En la Granja de San Ildefonso casi la totalidad de su territorio está incluido en la zona ZEPA (Zona de Especial Protección de Aves) y ha sido declarado Parque 
Nacional en el año 2013. También ha sido incluido en la Red de Reservas de la Biosfera, ya que cuenta con especies protegidas como el águila imperial y el buitre negro. El Real Sitio de San Ildefonso tiene $5.008 \mathrm{Ha}$ dentro del Parque Nacional de Guadarrama, un 34,6\% del territorio. En la zona periférica de protección tiene $7.822 \mathrm{Ha}$ un 54\% del municipio. La declaración del Parque Nacional de la Sierra de Guadarrama ha supuesto cambios en la protección de los Montes de Valsaín. Parte de su superficie, 3.326 ha, se han incorporado al Parque Nacional, y las 7.011 ha incluidas dentro de la Zona Periférica de Protección adquieren un régimen jurídico especial, similar al de un Parque Nacional, excepto en lo que al aprovechamiento forestal comercial de madera y al aprovechamiento hidroeléctrico del Salto del Olvido se refiere. En la Red Natura de la Junta de Castilla y León (2000) (https://rednatura.jcyl.es/natura2000/inicio.html), tanto Riofrío como Valsaín son ZEPA y LIC y San Ildefonso está en el límite entre ZEPA y LIC.

Por tanto, los parajes naturales de estos Reales Sitios constituyen una importante unidad ecológica bien preservada que permite enlazar estos terrenos con los del Real Sitio de El Escorial. En las Figuras 2, 3 y 4 se observa cómo todos estos parajes continúan unidos mediante áreas arboladas.

\subsubsection{Real Sitio de Aranjuez}

Frente a los Reales Sitios localizados al noroeste de Madrid, Aranjuez tiene un paisaje totalmente diferente. Situado en la confluencia de los ríos Tajo y Jarama, en el sureste de la Comunidad de Madrid, la localidad se asienta en la vega del río Tajo. Rodeado por cerros de materiales calizos y yesos con una vegetación rala y esteparia, la vega está fuertemente antropizada. En ella se mezclan la vegetación higrófila, que constituye bosques en galería, con las parcelas de cultivos de regadío, un paisaje caracterizado por sotos y huertas. Las vegas del río Tajo, incluidas en el Real Sitio de Aranjuez, tienen gran importancia ecológica, puesto que albergan una gran biodiversidad y permiten el intercambio de fauna a través de los corredores fluviales (Figuras 2, 3 y 4).

Los orígenes del Real Sitio se remontan a la Baja Edad Media, cuando Maestres de la Orden de Santiago construyeron un pequeño palacio dotado de huertas y jardines. El palacio, y la posesión, pasaron a dominio real en el reinado de los Reyes Católicos. Posteriormente, en la época de Carlos I, se inició el programa constructivo para dotar al lugar de una espaciosa residencia real, y se acometieron importantes obras para establecer la red hidráulica que transformó la huerta comprendida entre el Tajo y el Jarama en un vergel. Desde el siglo XVI fue un lugar de recreo para la familia real. Al igual que en los otros Reales Sitios, los Borbones reformaron y ampliaron los jardines palaciegos y el área edificada. Un cambio decisivo se produjo a mediados del siglo XVIII, cuando Fernando VI autorizó el libre establecimiento de personas en Aranjuez. A partir de 1752 se inició la construcción de una población de trazado regular, al sur y al este del Palacio Real, siguiendo los presupuestos ilustrados, que creció con vigor en pocas décadas. El Real Sitio de Aranjuez ofrecía a mediados del siglo XIX, un paisaje intensamente humanizado. El levantamiento topográfico ejecutado por la Junta General de Estadística ha permitido conocer los usos del suelo en aquel lugar, que tenía una superficie próxima a las 19.000 ha. Dos tercios del terreno estaban ocupados por sotos arbolados y monte bajo, pero los cultivos y tierras de labor tenían una presencia mucho más destacada que en las otras posesiones reales. En 1865 se dedicaban 2.211 hectáreas a cereal, 1.453 a pastos y 605 a olivar y viñedos. Y aún más significativo, los jardines ocupaban 152 hectáreas, y los ríos, arroyos y acequias otras 979 hectáreas, un 5\% de la superficie total (Urteaga y Camarero, 2015).

El paisaje de Aranjuez es muy característico y es representativo del Sureste de Madrid. Constituido por sedimentos de yesos y lutitas rojas y verdes (IGME, 2010) sobre los que se desarrollan Gipsisoles cálcicos, Calcisoles háplicos y Regosoles cálcáricos, tienen vegetación gipsícola y halófita con numerosos endemismos. Además, en las vegas de los ríos Tajo y Jarama se localizan arenas y gravas del cuaternario con formación de Fluvisoles y vegetación higrófila de ribera o cultivos de regadío. La clase agrológica de estas vegas corresponde a la categoría A, muy fértiles, pero al sur, en el mar de Ontígola, corresponde a las categorías C o D con riesgo de erosión y salinización y hacia el norte de la ciudad, categorías B y D con riesgo de erosión (Monturiol y Alcalá, 1990b). Son espacios que cuentan con una gran riqueza en aves, insectos y mamíferos acuáticos.

Los sotos tienen una gran biodiversidad y, aunque son áreas de protección ZEPA, están muy condicionados por el uso que se hace como vía de entrada a la ciudad. En las huertas dominan las llanuras aluviales, las terrazas y los fondos de valle. Se diseñaron en época de Felipe II y, fueron ampliadas durante el reinado de los Borbones, quienes buscaban la armonía del territorio de Aranjuez mediante la vegetación. 
Carlos III las propuso para verificar los modelos de explotación agronómica de la época, es decir, se trataba de un campo experimental donde se plasmaban las ideas fisiocráticas, agrícolas, ganaderas, científicas y sociales que sirvieron para activar el progreso en este lugar, desde una visión ilustrada (Martínez-Atienza, 1999). Tradicionalmente, la huerta se basaba principalmente en los cultivos de regadío, habiendo quedado relegada en la actualidad, por la importante urbanización que ha sufrido este espacio.

El valor singular de las huertas y los sotos hizo que fueran declarados Conjunto Histórico Artístico en 1983, y considerados Bienes a Proteger, por su originalidad, según el Plan General de Ordenación Urbana de Aranjuez de 1996. Además, debido a que los sotos son uno de los ecosistemas más complejos y valiosos por su capacidad de albergar especies vegetales y animales, han sido merecedores de la protección de la UE a través de los "Carrizales, sotos de Aranjuez, Cortados y Cantiles de los ríos Jarama y Manzanares" y las de "Zonas de Especial Protección de Aves". En los sotos se empezaron a trazar paseos en el siglo XVI y en la actualidad hay más de $30 \mathrm{~km}$. Se inician, entre las confluencias de los ríos Tajo y Jarama, con Felipe II, continúan con Felipe III y finalizan con Carlos III. Servían para separar áreas de cultivos, para pasear y para acceder a determinados lugares. Sus árboles se explotaban como madera. Del sotobosque original aún se conservan las formaciones vegetales más próximas al cauce como especies arbóreas como el álamo y el fresno acompañadas por un rico estrato arbustivo y herbáceo entre los que destacan los sauces, tarayes, majuelos, zarzamoras (http://www.aranjuez.es/).

Aunque siempre se ha dado más valor a los sotos y huertas incluidos en el Real Sitio, también es importante preservar el paisaje de cuestas, páramos y lagunas que rodean al municipio caracterizados por vegetación calcícola, gipsícola y halófita, con numerosas especies endémicas y gran valor ecológico (Martínez, Martín, Romero y García, 2003) y que funcionan también como corredores ecológicos. Estas unidades paisajísticas son consideradas "Lugares de Interés Comunitario" (LIC) y el Regajal y el Mar de Ontígola cuentan con la declaración de Reserva Natural que protege un enclave natural de gran valor, tanto por su importancia natural, como urbanística. El Mar de Ontígola se construyó como un embalse desde el que se regaban las huertas y los jardines en el siglo XVIII. Esta zona cuenta, mediante la Ley 7/1990 de 28 de junio, con un régimen específico establecido para la protección de los embalses y de las zonas húmedas de la Comunidad de Madrid y desde el año 1994 es considerado Espacio Protegido, poniendo de manifiesto sus valores históricos, medioambientales y botánicos, especialmente, entomológicos. Tiene numerosos endemismos.

La Delegación de Medio Ambiente, Parques y Jardines y Agricultura señala en el Libro Blanco de Aranjuez (2015) que de una superficie total de 18.902,47 ha, Aranjuez cuenta con 15.426,53 hectáreas incluidas en el Espacio Protegido Red Natura 2000 lo que supone un porcentaje de 81,61 \% de su territorio incluido en Zona de Especial Conservación (ZEC). La declaración como Zona Especial de Conservación (ZEC) del Lugar de Importancia Comunitaria "Vegas, Cuestas y Páramos del Sureste de Madrid" está regulada por Decreto 104/2014, de 3 de septiembre, del Consejo de Gobierno, en donde se aprueba el Plan de Gestión y el de las Zonas de Especial Protección para las Aves "Carrizales y Sotos de Aranjuez" y "Cortados y Cantiles de los ríos Jarama y Manzanares" y Reserva Natural El Regajal-Mar de Ontígola. Se trata de parajes de excepcional importancia faunística. El Regajal constituye un enclave natural donde existen elementos botánicos y entomológicos (como algunas mariposas endémicas muy amenazadas) de extraordinario valor. El Mar de Ontígola es de gran importancia para la avifauna acuática, que encuentra en esta zona húmeda refugio entre la vegetación palustre que se extiende por la mayor parte de su superficie.

La inclusión de Aranjuez en la Lista del Patrimonio de la Humanidad de la UNESCO como Paisaje Cultural de la Humanidad, en el año 2001, reconoce la riqueza paisajística y medioambiental de este lugar, así como la manera en la que se ha sabido unir un importante paisaje humanizado — ciudad y huertas- con un entorno natural de gran valor, como es el de las vegas. Además, esta inclusión muestra la importancia que en la actualidad adquiere el valor medioambiental y refuerza el atractivo del conjunto de sotos y huertas históricos. La combinación de la vegetación típica de ribera (sauces, álamos, olmos, etc.) y de huertas, son los elementos naturales que definen fundamentalmente el contenido paisajístico (Mínguez, 2007).

\section{Discusión}

Sorprende, al realizar este trabajo y consultar la bibliografía sobre Reales Sitios, la escasa documentación existente en cuanto a los entornos naturales que los rodean, ya que la ubicación de los Reales Sitios ha dependido, en gran medida, del valor de su entorno natural. En la mayoría de los casos su origen se remonta a una utilización como cotos de caza por parte de la nobleza, lo que los vinculó desde el inicio a 
la importancia de su medio natural. Esto no solo ha sucedido en España, sino también en otros lugares de Europa donde han existido bosques adscritos a las casas reales, como señala Maroteaux (2000).

Así, los Reales Sitios, muy estudiados en cuanto a su patrimonio histórico, artístico y turístico, con la existencia de una amplísima bibliografía, apenas han sido analizados en cuanto a su función para preservar el medio natural, conservar los suelos y mantener la biodiversidad y los corredores ecológicos que faciliten el movimiento de la fauna. Este es un ejemplo de la necesidad, como en tantos otros estudios, de trabajos multidisciplinares entre investigadores de ciencias naturales, sociales y humanidades.

De todos los Reales Sitios localizados en España son, quizás, los situados en los alrededores de la ciudad de Madrid, los que más riesgo tienen en cuanto a la desaparición de sus ecosistemas originales. La conversión de Madrid en un centro político y económico, como consecuencia de la instauración de la capital allí desde 1561 hasta 1601 y, de nuevo, desde 1606, ha llevado a un incremento importante de la población a lo largo de los siglos, especialmente, en el siglo XX. Además, el desarrollo económico unido a la capitalidad ha conducido no solo a una gran expansión urbanística, sino también industrial, con el consiguiente desarrollo de infraestructuras viarias. Todo esto implica un gran sellado de suelo que reduce la extensión de los espacios naturales. A pesar de ello, y gracias a la presencia de los Reales Sitios, con su alto nivel de protección se ha impedido que este sellado sea mayor. Así, se conservan grandes espacios naturales, con alto valor ambiental, dentro del municipio de Madrid, gracias al Real Sitio de El Pardo, y espacios protegidos en el noroeste de la Comunidad y este de la provincia de Segovia gracias a los Reales Sitios de El Escorial, Riofrío y La Granja de San Ildefonso. En el sur de la Comunidad de Madrid, espacio altamente antropizado, se pueden conservar algunos parajes naturales y paisajes históricos de huertas y sotos gracias al Real Sitio de Aranjuez. Debido a la situación de estos Reales Sitios el crecimiento de la ciudad de Madrid y su área metropolitana, durante los últimos siglos, ha sido, sobre todo, hacia el este, sur y norte, con menor desarrollo urbanístico e industrial hacia el noroeste y oste. Además, hay una diferencia en el tipo de ocupación, encontrándose en las zonas oeste y noroeste las urbanizaciones más abiertas, con menor densidad de edificación y menor uso industrial lo que hace que el sellado del suelo sea menos agresivo. Las poblaciones que se instalan en estos lugares tienen un poder adquisitivo mayor y mejor calidad ambiental. En Madrid, como se puede observar comparando las imágenes del satélite Landsat del año 1989 frente a las del 2010, (Figura 5, García, Pérez y Guerra, 2014) el sellado de suelo (en tonos azul oscuro en las imágenes) se produce sobre todo de forma concéntrica en el área más próxima a la conurbación central, siguiendo al desarrollo de las grandes infraestructuras viarias. Sin embargo, este sellado no es simétrico, ya que es más acusado hacia el este y sur, como se observa en la Figura 6, en la que aparece en negro la superficie que se ha sellado entre ambas fechas. En 2018 la conurbación de Madrid (García-Alvarado, Pérez y García, 2020) ya consumió de media el 18,5 \% del suelo, con grandes variaciones espaciales (13,33\% al norte y $41,41 \%$ al sur).Cabe resaltar también que el municipio de Madrid no tiene apenas crecimiento hacia el norte (García y Pérez, 2016) debido al freno que supone el Real Sitio de El Pardo, manteniéndose por tanto dos grandes pulmones verdes en la capital: el Monte de El Pardo y la Casa de Campo (sitio adscrito en la Edad Moderna a la realeza). Este freno urbanístico debido al Real Sitio se produce también en otros municipios localizados al norte de la capital, como es el caso de Colmenar (Arístegui y Pérez, 2017). La presencia de El Pardo no solo ha frenado el desarrollo de las urbanizaciones, sino que también ha condicionado el establecimiento de infraestructuras viarias. Así, las autovías M30 y M40 han sido soterradas en varios kilómetros que atraviesan estos lugares.

En el oeste de la Comunidad de Madrid también el crecimiento urbano se encuentra frenado en las inmediaciones del Real Sitio de El Escorial gracias a la concesión de distintas figuras de protección del patrimonio histórico y ambiental. Así, los bosques de pinos y robles del Paraje Pintoresco del Pinar de Abantos y Zona de la Herrería y de Cuelgamuros, que constituyen el área declarada como Lugar de Importancia Comunitaria LIC Cuenca del río Guadarrama", forman un corredor natural entre las Zonas de Especial Protección para las Aves "Encinares de los ríos Alberche y el Cofio" y "Monte de El Pardo", creando un área de colchón y de interconexión de gran importancia para alguna de las especies de aves más importantes. Los reales Sitios de la Granja de San Ildefonso y Riofrío, al localizarse en parte dentro del Parque Nacional de Guadarrama tienen además una protección añadida siguiendo los protocolos del Plan de Ordenación de los Recursos Naturales (PORN) del Espacio Natural «Sierra de Guadarrama» que tiene como finalidad establecer las medidas necesarias para asegurar la protección, conservación, mejora y utilización racional de este espacio y mantener los valores paisajísticos, en armonía con los usos, derechos y aprovechamientos tradicionales y con sus valores históricos y culturales. 
Figura 5. Imágenes en falso color del satélite Landsat 5, 25-03-1989 y 6-05-2010. Bandas 5-4-1 (R-V-A)

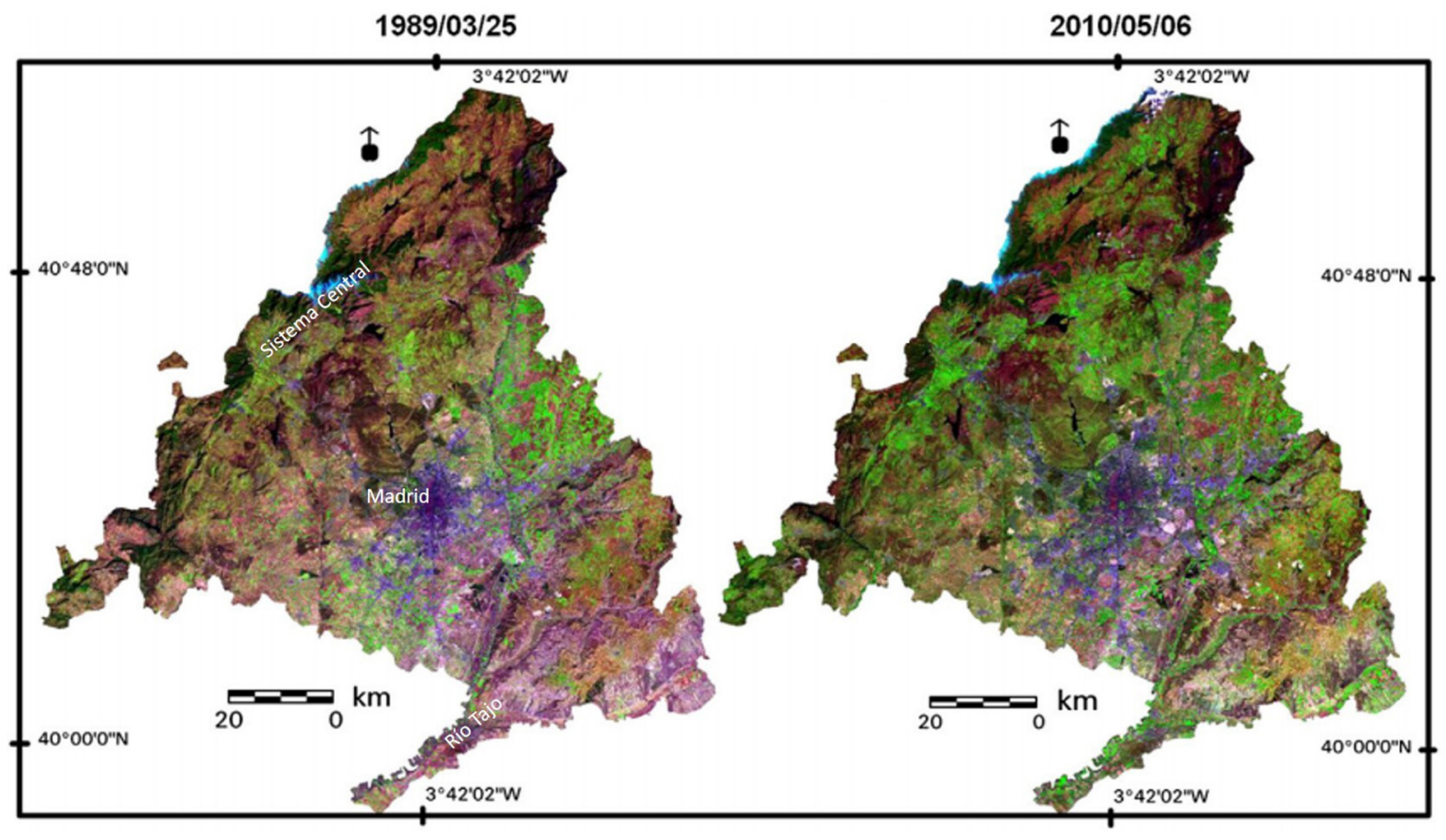

Fuente: García, Pérez y Guerra (2014)

Figura 6. Sellado de suelo entre el 25-03-1989 y 6-05-2010

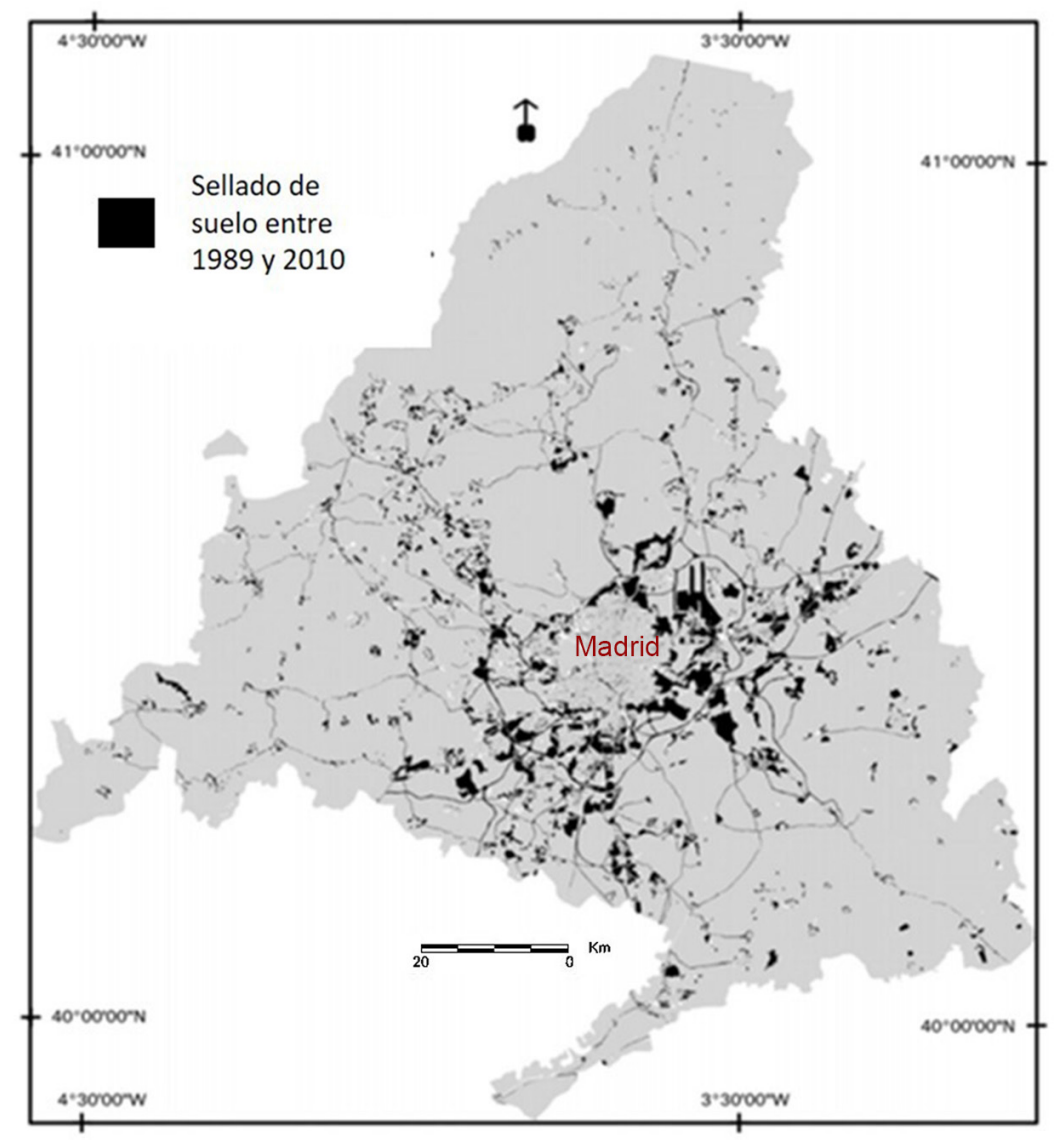

Fuente: García, Pérez y Guerra (2014). Elaboración propia 
Aun así, si se comparan los espacios naturales actuales con los presentes en siglos pasados se observa que han disminuido su extensión y, lo que resulta más peligroso para los organismos, se han roto los mosaicos de vegetación y los corredores ecológicos que facilitaban el libre intercambio de fauna. La fragilidad de muchos de los suelos, umbrisoles, leptosoles y cambisoles en los Reales Sitios del Noroeste y gipsisoles, calcisoles y regosoles en el Sur han llevado también a un incremento de la degradación y disminución de la vegetación asociada. Como señalan García-Alvarado, Pérez y García (2020), hay que intentar una mayor integración entre la ocupación urbana y su entorno naturalizado, generando menor huella ecológica y un mayor valor de resilencia frente a fenómenos catastróficos. Tanto por Patrimonio Nacional como por los planes de protección de la Comunidad de Madrid se intenta mantener la dinámica y estructura funcional de los ecosistemas que conforman los parajes naturales de los Reales Sitios, restaurando las áreas degradadas y garantizando la persistencia de la diversidad genética, en especial de las especies amenazadas. Es fundamental hacer compatible las distintas actividades de estos lugares: uso residencial, turístico y recreativo, actividad cinegética y explotación agraria, forestal e hidroeléctrica, con la conservación de los recursos naturales.

A pesar de todas las figuras de protección que, en principio, aseguran el mantenimiento del patrimonio natural de los Reales Sitios, estos no dejan de tener riesgos ya que, aunque tienen unos ecosistemas maduros, desarrollados a lo largo de los siglos, son muy vulnerables. Su proximidad con la capital de España, con la voracidad urbanística que esto implica y la necesidad de construir infraestructuras en un sistema tan centralizado como es el de este país son el principal peligro que acecha a estos lugares. Aunque tanto autovías como líneas del ferrocarril se han construido bajo tierra en la mayor parte de estos territorios, las carreteras próximas constituyen una barrera para la fauna. Los incendios y la reforestación, no siempre correcta, condicionan el mantenimiento y desarrollo de los bosques. La fragilidad de los suelos, poco espesos y con textura arenosa facilita su erosión, condicionando así el desarrollo de los distintos estratos de vegetación. Evidentemente, el turismo que, en gran medida permite el mantenimiento económico de estos lugares, puede también amenazar su conservación. si no está bien regulado. A pesar de todo ello hay que ser optimistas, aunque el patrimonio natural ha sufrido muchos avatares y se ha reducido su extensión a través de los siglos (ventas de terrenos por necesidades económicas, desamortizaciones, instalación de industrias, desarrollo de áreas urbanas, etc.), sigue manteniendo un importante territorio de gran valor cultural, paisajístico y ecológico. En el mundo actual, hay muchas medidas de preservación que se están aplicando, que no existían en el pasado, y que permitirán su conservación para futuras generaciones.

El sellado del suelo es una de las mayores agresiones medioambientales. Es probable que cuando se planificaron los Reales Sitios no se pensara en el freno que iban a suponer frente a esta agresión, pero lo cierto es que han pasado a ser fundamentales en la ordenación del desarrollo urbano, permitiendo una gran permeabilidad ecológica entre estos espacios y su entorno.

Los espacios naturales protegidos y su conectividad ecológica pueden ser uno de los retos medioambientales más importantes para mantener la geodiversidad, el patrimonio natural y el patrimonio cultural. Así, estos Reales Sitios, localizados en áreas montañosas o corredores fluviales pueden constituir redes muy permeables y dotar de hábitats continuos a especies que, en muchos casos, están en peligro de extinción. Aunque la ley reguladora de Patrimonio Nacional 23/1982 establece que cada uno de los bienes con especial valor ecológico debe contar con un Plan de Protección Medioambiental, esto no se cumple en el caso de todos los Reales Sitios.

En el estudio realizado se han utilizado los datos que otros autores (Aréstegui y Pérez, 2017; Urteaga y Camarero, 2014a, 2014b y 2015) han obtenido estudiando los archivos del Instituto Geográfico Nacional y se han seleccionado imágenes históricas y actuales de distintos servidores para ver la evolución. De todas las fuentes utilizadas, para trabajar con más precisión se ha seleccionado la imagen del satélite Landsat 8, ya que facilita una visión general de todos estos Reales Sitios y, al tener una gran resolución espectral, permite, con la combinación de los distintos canales y la obtención de índices, una mejora de la visualización de las áreas estudiadas, así como la obtención de una clasificación precisa.

La utilización de la teledetección, junto con otras fuentes de imágenes, resulta, pues, muy útil para este tipo de trabajos en el que es importante analizar la evolución de los ecosistemas. En futuros trabajos se pueden utilizar otros satélites y sensores con alta resolución espacial y espectral como el satélite Sentinel. También podría resultar útil el uso de imágenes obtenidas con un dron, si bien no siempre es factible realizar vuelos en lugares tan protegidos. 


\section{Conclusiones}

Desde su creación, la mayoría de los Reales Sitios se rodearon de grandes extensiones de bosques y prados que han preservado a lo largo de la historia, impidiendo la destrucción de numerosos hábitats localizados cerca de grandes ciudades. Gracias a ellos en la Comunidad de Madrid existe una gran superficie de espacios naturales, aun cuando la presión de la capital y su área metropolitana haya producido un gran incremento del sellado del suelo en los últimos siglos.

Gracias a la protección de Patrimonio Nacional se han preservado importantes masas forestales de coníferas y caducifolias en las áreas de montaña y de bosques mediterráneos caracterizados por las formaciones durilignosas de encinas y coscojas en la cuenca terciaria. También se han protegido suelos muy frágiles: cambisoles, arenosoles, regosoles y umbrisoles, con alto riesgo de erosión.

Aunque a lo largo de los siglos ha disminuido la extensión de los espacios naturales de los Reales Sitios, en la actualidad se impide el sellado de los suelos en su territorio, preservando los bosques autóctonos y permitiendo la comunicación de la fauna entre ellos. Es importante resaltar que, gracias al patrimonio natural de estos lugares, se ha obligado al soterramiento de algunas infraestructuras que, de no ser así, habrían ejercido de importante barrera para la fauna. Además, el que la mayoría de estos Reales Sitios estén considerados como Reservas de la Biosfera permite una mayor protección condicionando aún más la intervención humana.

En el área de estudio hay unas 86.000 hectáreas de suelo sellado, frente a 512.000 de vegetación natural.

En el momento de mayor extensión y desarrollo del sistema de los Reales Sitios, durante los reinados de Carlos IV y Fernando VII, una parte importante de sus entornos naturales estaban conectados, en concreto los de El Escorial, la Granja de San Ildefonso, Riofrío y El Pardo. Este corredor verde incluía también otros enclaves naturales que, en ese momento, formaban parte de los Reales Sitios, como el Soto de Viñuelas, la Casa de Campo y el Real Sitio de la Florida. En la actualidad estos lugares están fragmentados, como se puede observar en las imágenes de satélite y ortofotos actuales; algunos de ellos han desaparecido debido a la presión urbanística de la ciudad de Madrid, aislándose el Real Sitio de El Pardo de los Reales Sitios de El Escorial y La Granja de San Ildefonso. Aun así, a través del Parque Nacional de la Sierra de Guadarrama y del Parque Regional del Manzanares hay conexiones entre ellos, lo que ha permitido establecer zonas de LICS y ZEPAS que, al estar protegidas, permiten la interconexión biológica y evitan que estas áreas sean urbanizadas.

En el caso de Aranjuez se preserva no solo un paisaje cultural, en el que hay una estrecha relación entre paisaje natural y antropizado, como es el caso de las huertas y sotos, sino también áreas con una gran biodiversidad. Así, la creación de una presa en Ontígola, ampliando una balsa anterior realizada por Felipe II, ha dado lugar a un humedal y reserva natural protegida por la Comunidad de Madrid con una gran diversidad tanto de invertebrados como de aves, anfibios y reptiles y de especies vegetales palustres y halófitas características. También los suelos sufren alto riesgo de degradación tanto por procesos de sellado, como por salinización, pero la presencia del Real Sitio ha impedido su destrucción.

Quizás sea el municipio de Madrid el más beneficiado por la presencia de un Real Sitio ya que tiene un importante patrimonio verde, con más de 600 hectáreas de parques y jardines, muchos de ellos históricos. La presencia de un Real Sitio, El Pardo y de otro lugar que fue patrimonio de la nobleza, La Casa de Campo, representan los dos grandes pulmones verdes de la ciudad y ejercen de corredores ecológicos con otros hábitats situados en el Norte y este de la Comunidad.

La irregular distribución del suelo sellado en la Comunidad de Madrid obliga a que las propuestas para mitigación de la huella ecológica deberán ser también dispares, atendiendo a esta distribución. En el este y sur el sellado llega prácticamente hasta el límite de la Comunidad de Castilla la Mancha, respetando el Real Sitio de Aranjuez, mientras que en el norte y oeste se encuentra limitado, en parte, por la presencia de los Reales Sitios y los parajes naturales que los rodean

Las imágenes de satélite facilitan la cartografía de las áreas naturales y de los suelos sellados y permiten hacer un seguimiento de su evolución, comparándola con los datos de los planos históricos. Mediante el estudio de estas imágenes se cartografía el sellado del suelo, principal responsable de la fragmentación del territorio y de la disminución de los espacios naturales. 
El estudio de la evolución paisajística de los Reales Sitios demuestra cómo la conservación del patrimonio histórico, artístico, ecológico y geológico va unida en numerosas ocasiones y debe analizarse desde una perspectiva multidisciplinar. Esta simbiosis entre patrimonio natural y cultural es fundamental para entender la evolución y preservación de estos lugares.

Los Reales sitios representan pues, uno de los mejores ejemplos de que la conjunción de medidas de protección del patrimonio cultural y las de protección del patrimonio natural permiten preservar los ecosistemas en áreas con un alto riesgo de intervención antrópica.

En este trabajo se ha intentado dar una visión general de la importancia de los Reales Sitios en la preservación del territorio. Sería aconsejable que investigadores de distintas especialidades colaboraran en un estudio más detallado de la evolución de cada uno de estos lugares, teniendo en cuenta todo su desarrollo histórico y la cartografía que se puede consultar en diversos archivos como los de Patrimonio Nacional y los del Instituto Geográfico Nacional. Esta información será de gran utilidad, unida a los estudios sobre su situación actual, para tratar de prevenir los riesgos que pueden afectarles. Las Tecnologías de la Información Geográfica y la posibilidad de manejar un importante volumen de datos mediante la inteligencia artificial facilitarán de forma notable esta tarea.

\section{Referencias}

Agencia Europea de Medio Ambiente (AEMA) (2012). Documento de trabajo de los servicios de la Comisión. Directrices sobre mejores prácticas para limitar, mitigar o compensar el sellado del suelo (Brussels, 15.5.2012, SWD (2012) 101 final/ 2). Recuperado de https://ec.europa.eu/environment/soil/pdf/ guidelines/pub/soil_es.pdf

Añó, C., Pascual, J.A. y Sánchez, J. (2005). Capacidad de uso y sellado antropogénico del Suelo en la franja litoral de la provincia de Castellón. Investigaciones Geográficas, 38, 65-77. https://doi.org/10.14198/ INGEO2005.38.04

Aranjuez, Ayuntamiento del Real Sitio y Villa. http://www.aranjuez.es/turismo/rutas/ruta-natural/

Aréstegui, A. y Pérez, M.E. (2017). Soil sealing in Madrid, study case of Colmenar Viejo. Earth Sciences Research Journal, 21(3), 111-116. http://dx.doi.org/10.15446/esrj.v21n3.51450

Artmann, M. (2014). Assessment of soil sealing management responses, strategies, and targets toward ecologically sustainable urban land use management. Ambio, 43(4), 530-541. https://doi.org/10.1007/ s13280-014-0511-1

Base Referencial Mundial del Recurso Suelo (2015). http://www.fao.org/soils-portal/soil-survey/ clasificacion-de-suelos/base-referencial-mundial// es.

Bonet, A. (2000). Felipe V e Isabel de Farnesio y el Real Sitio de La Granja de San Ildefonso: de retiro real a "pastel de nieve". En Patrimonio Nacional (Edit.), El Real sitio de la Granja de San Ildefonso: retrato y escena del Rey (pp.16-24). Madrid: Patrimonio Nacional.

Caballero, A. (2017). Sellado de suelos en la comarca del Mar Menor (Murcia). Consecuencias ambientales (Tesis Doctoral). Murcia: Universidad de Murcia. Recuperado de https://digitum.um.es/digitum/ handle/10201/53752

Checa, F. y Morán, J. M. (1986). Las Casas del Rey. Casas de campo, cazaderos y jardines. Siglos XVI y XVII. Madrid: Ediciones El Viso.

Chueca, F. (1989a). Los Reales Sitios en torno a Madrid. Reales Sitios, 100 (Número extraordinario XXV Aniversario), 47-56.

Comunidad Autónoma de Madrid (C.A.M.). (2007). Cartografía medioambiental de la Comunidad de Madrid. Madrid: Secretaría General Técnica de la Comunidad de Madrid. Recuperado de https://www. comunidad.madrid/servicios/urbanismo-medio-ambiente/cartografia-ambiental

Comunidad Autónoma de Madrid (C.A.M.). (2010). Planificación de la red de corredores ecológicos de la comunidad de Madrid: identificación de oportunidades para el bienestar social y la conservación del patrimonio natural. Madrid: Consejería de Medio Ambiente, Vivienda y Ordenación del Territorio. Dirección General de Urbanismo y Estrategia Territorial. Recuperado de http://www.madrid.org/ cartografia/planea/planeamiento/html/web/corredores.htm 
Comunidad Autónoma de Madrid (C.A.M.) https://www.aranjuez.es/images/files/medioambiente/ libroblanco.pdf. Delegación de Medio Ambiente, Parques y Jardines y Agricultura. (2015). Libro blanco sobre biodiversidad y conservación del patrimonio natural de Aranjuez. Aranjuez. Ayuntamiento del Real Sitio y Villa.

Comunidad Autónoma de Madrid (C.A.M.). (2021). Anuario Estadístico de la Comunidad de Madrid. 1985-2021 Urbanismo, vivienda y construcción. http://www.madrid.org/iestadis/fijas/estructu/ general/anuario/ianucapl0.htm

Forteza J., García A., Lorenzo, L., Najac, N., Cuadrado, S., Ingelmo, F., .. y Rivas, D. (1987). Mapa de suelos de Castilla León. Junta de Castilla y León. Escala 1:500.000. Valladolid: Junta de Castilla y León.

Gallardo J., Álvarez, A. y Cala, V. (1988). Horizontes de fragipán de tipo "ison". Formados por permafrost en la sierra de Guadarrama. Estudios Geológicos, 44, 83-91. https://doi.org/10.3989/egeol.88441-2526

García, M. y Mínguez, M.C. (2004). Funcionalidad Turística de los Reales Sitios españoles: Problemas y Perspectivas. Ería, 66, 71-84.

García-Alvarado, J.M., García, M. P. y Pérez, M. E. (2018a). Evaluación y medida del sellado de suelos en los Programas de Actuación Urbanística (PAUS) del norte de Madrid (España). Boletín de la Asociación de Geógrafos Españoles 76, 1-19. https://doi.org/10.21138/bage.2513

García-Alvarado, J.M., García, M. P.y Pérez, M. E. (2018b). Sellado de suelos a partir de teledetección y SIG en el Programa de Actuación Urbanística (PAU) del sudeste de Madrid (España). Cuadernos Geográficos, 57(1), 39-60. http://dx.doi.org/10.30827/cuadgeo.v57i1.5360.

García-Alvarado, J. M., Pérez M. E., y García, M. P. (2020). Sellado de suelos, fragmentación y conectividad ecológica en la conurbación de Madrid (España). Boletín de la Asociación De Geógrafos Españoles, 85. https://doi.org/10.21138/bage.2884

García, M.P. y Álvarez, B. (2020). Los Reales Sitios y su importancia en la conservación del suelo. Spanish Journal of Soil Science, 10, 3. https://doi.org/10.3989/egeol.88441-2526

García, M.P. y Pérez, M.E. (2016). Mapping of soil sealing by vegetation indexes and built-up index: A case study in Madrid (Spain). 214-215, Geoderma, 268, 100-107. https://doi.org/10.1016/j. geoderma.2016.01.012

García, M.P., Pérez, M.E. y Guerra, A. (2014). Using TM images to detect soil sealing change in Madrid (Spain) Geoderma, 135-140. https://doi.org/10.1016/j.geoderma.2013.09.017

Gardi, C., Montanarella, L., Tóth, G., Palmieri, A., Martino, L. y Erhard, M. (2011). The Assessment of Soil Sealing and Land Take in Europe. En G. Tóth y T. Németh (Eds.), Land Quality and Land Use Information in the European Union (pp. 173-186). European Comission, Publications Office of the European Union.

Gómez, J. y Atienza, J.M. (1998). Aranjuez: de Real Sitio a ciudad industrial en declive. Oportunidades inéditas de un emplazamiento estratégico. Urban, 2, 107-115.

Herrera, P. y Díaz, E. (2013). Ecología del paisaje, Conectividad ecológica y territorio. DOSSIER ciudades, $1,43-70$.

Hortal J.E. (2014). La integración de los sitios reales en el sistema de corte durante el reinado de Felipe IV. Librosdelacorte.es, 8, 27-47.

Hortal, J.E. (2017). La unión de la Corte, la Casa y el Territorio en la Monarquía Hispana de los siglos XVI y XVII: Las Guardas Reales y los Sitios Reales. Revista Escuela de Historia, 16(1). https://www. academia.edu/35858226/.

Instituto Geográfico Nacional. Plan Nacional de Ortofotografía aérea (PNOA). http://www.ign.es

Instituto Geológico y Minero de España (I.G.M.E). (1989). Mapa Geológico Nacional (MAGNA). Hoja 559. Madrid. Escala 1:50.000. Madrid: Instituto Geológico y Minero de España.

Instituto Geológico y Minero de España (I.G.M.E.) (1990). Mapa Geológico Nacional (MAGNA). Hoja 533. San Lorenzo de El Escorial. Escala 1:50.000. Madrid: Instituto Geológico y Minero de España.

Instituto Geológico y Minero de España (I.G.M.E.) (1991). Mapa Geológico Nacional (MAGNA). Hoja 483. Segovia. Escala 1:50.000. Madrid: Instituto Geológico y Minero de España. 
Instituto Geológico y Minero de España (I.G.M.E.) (2000). Mapa Geológico Nacional (MAGNA). Hoja 534. Colmenar Viejo. Escala 1:50.000. Madrid: Instituto Geológico y Minero de España.

Instituto Geológico y Minero de España (I.G.M.E.) (2010). Mapa Geológico Nacional (MAGNA). Hoja 605. Aranjuez. Escala 1:50.000. Madrid: Instituto Geológico y Minero de España.

Junta de Castilla León (2000). Natura 2000 en Castilla León. Recuperado de http://rednatura.jcyl.es/ natura2000/Mapas\%20generales/MAPAsegovia_2.pdf

Jiménez R., García, G., Polo A. y Almendros G. (1981). Edafogénesis catenal de las formaciones edáficas del valle de Valsaín. (Vertiente Norte de la Sierra de Guadarrama). Anales de Edafología y Agrobiología, XL (5-6), 833-848.

Labrador, F. y Rossi, P. (2014). Entre Reales Sitios de España, 'Coronas de delicias' de los Saboya y residencias napolitanas de los Borbones. En L. D'Alessandro, F. Labrador y P. Rossi (Eds.), Siti Reali in Europa. Una storia del territorio tra Madrid e Napoli (pp. 33-40). Napoli: Fondazione Roma Mediterraneo - Università Suor Orsola Benincasa.

López Ontiveros, A. (1993). Importancia de la geografía cinegética en el contexto de la geografía agraria española), En A. Gil Olcina, A. Morales iGil (Eds), Medio siglo de cambios agrarios en España (pp. 91-216). Instituto de Cultura 'Juan Gil Albert'. Alicante.

Martínez-Atienza, R. (1999). Arquitectura y desarrollo urbano. Madrid. Comunidad de Madrid.

Martinez J., Martín, M.P., Romero. R. y García, J.A. (2003). Valoración del paisaje en la Zona de Especial Protección de Aves. Carrizales y Sotos de Aranjuez (Comunidad de Madrid). Geofocus, 3,1-21.

Maroteaux, V. (2000). Versailles le Roi et son Domaine. París: Editorial Picard.

Monturiol, F. y Alcalá, L. (1990a). Mapa de asociaciones de suelos de la Comunidad de Madrid, Escala 1:200,000. Madrid: CSIC, CAM.

Monturiol, F. y Alcalá, L. (1990b). Mapa de Capacidad Potencial de Uso Agrícola de la Comunidad de Madrid, Escala 1:200,000. Madrid: CSIC, CAM.

Mínguez, M.C. (2007). Patrimonio cultural y turismo en los reales sitios de la Comunidad de Madrid y sus incidencias en el territorio (Tesis Doctoral). Universidad Complutense de Madrid, Facultad de Geografía e Historia. Madrid.

Munafo, M., Norero, C., Sabbi, A. y Salvati, L. (2010). Soil Sealing in the Growing City: A Survey in Rome, Italy. Scottish Geographical Journal, 126(3), 153-161. https://doi.org/10.1080/14702541.2010.527855

Munafo, M., Salvati, L. y Zitti, M. (2012). Estimating soil sealing rate at national level. Italy as a case study. Ecological Indicators, 26, 137-140. https://doi.org/10.1016/j.ecolind.2012.11.001

Nicolás A. y Gandullo J.M. (1969). Ecología de los pinares españoles. II. Pinus sylvestris L. Madrid. Ministerio de Agricultura. Inst. Forest. Invest. y Exper.

Patrimonio Nacional (1997). Plan de Protección medioambiental del Monte de El Pardo. Recuperado de https://www.boe.es/eli/es/o/1997/07/31/(3)

Patrimonio Nacional. Plan de actuación 2017-2021. Recuperado de https://www.patrimonionacional.es/ patrimonio-abierto/plan-de-actuacion

Patrimonio Nacional. Reales Sitios. Recuperado de https://www.patrimonionacional.es/real-sitio.

Pérez, M.E. y García, M.P. (2016). Monitoring Soil Sealing in Guadarrama River Basin, Spain, and Its Potential Impact in Agricultural Areas. Agriculture, 6(1), 7. https://doi.org/10.3390/agriculture6010007

Pérez, M.E. y García, M.P. (2017). Monitoring soil erosion by raster images: from aerial photographs to drone taken pictures. European Journal of Geography, 7(5), 117-129.

Rodríguez, D. y Martínez, J. (2019). Analysing subtle threats to conservation: A nineteen-year assessment of fragmentation and isolation of Spanish protected áreas. Landscape and Urban Planning, 185, 107-116. https://doi.org/10.1016/j.landurbplan.2019.01.012

Romero, A., Belmonte, F, Docampo, A.M. y Ruiz, J.D. (2011). Consecuencias del sellado de los suelos en el Campo de Cartagena (Murcia). En V. Gozálvez Pérez . y J.A. Marco Molina (Coords.), Geografía y desafios territoriales en el siglo XXI, 2 (pp. 605-616). Alicante.Universidad de AlicanteLugar: Entidad editora. 
Romero, A., Caballero, A., y Pérez, A. (2017). Expansión urbana y turismo en la Comarca del Campo de Cartagena-Mar Menor (Murcia). Impacto en el sellado del suelo. Cuadernos de Turismo, 39, 521-546. https://doi.org/10.6018/turismo.39.290691

Sancho, J.L. (1995). La arquitectura de los Sitios Reales. Catálogo histórico de los palacios, jardines y patronatos reales del Patrimonio Nacional. Madrid: Patrimonio Nacional/Fundación Tabacalera.

Sancho, J.L. y Aparicio J.R. (2012). Real Sitio de La Granja de San Ildefonso y Riofrío. Madrid: Patrimonio Nacional.

Scalenghe, R. y Marsan, F. A. (2009). The anthropogenic sealing of soils in urban areas. Landscape and Urban Planning, 90(1-2), 1-10. https://doi.org/10.1016/j.landurbplan.2008.10.011

Shen, G., Abdoul, N.I., Zhu, Y., Wang, Z. y Gong, J. (2017). Remote sensing of urban growth and landscape pattern changes in response to the expansion of Chongming Island in Shanghai, China. Geocarto International, 32(5), 488-502. https://doi.org/10.1080/10106049.2016.1156166

Tovar, V. (2001). El Pardo. Madrid: Fundación Caja Madrid.

Urteaga L. y Camarero C. (2014a). Los planos de los sitios reales españoles formados por la junta general de estadística (1861-1869). Scripta Nova, XVIII (482).

Urteaga L. y Camarero C. (2014b). Planimetría del Real Sitio de San Ildefonso de la Junta General de Estadística, 1868-1869. Treballs de la Societat Catalana de Geografia,77, 299-317. http:// doi:10.2436/20.3002.01.64

Urteaga L. y Camarero C. (2015). The last topographical survey of the Royal Site of Aranjuez (1864-1868). In The 26th International Conference on the History of Cartography (pp. 12-17). Antwerp, Belgium.

United States Geological Survey. (USGS). http://glovis.usgs.gov/

Valera, A., Añó, C., y Sánchez, J. (2011). Cincuenta años (1956-2006) de crecimiento urbano y degradación de suelos por sellado antropogénico en el término municipal de Valencia. Anales de Geografía de la Universidad Complutense, 31(2), 177-191. https://doi.org/10.5209/rev_AGUC.2011.v31.n2.37016

Xiao, R., Su, S., Zhang, Z., Qi, J., Jiang, D., y Wu, J. (2013). Dynamics of soil sealing and soil landscape patterns under rapid urbanization. Catena, 109, 1-12. https://doi.org/10.1016/j.catena.2013.05.004 